\title{
THE NEUROLOGICAL MANIFESTATIONS \\ OF SJÖGREN'S SYNDROME: Diagnosis and Treatment
}

\author{
Robert I. Fox, M.D., Ph.D. \\ Chief, Rheumatology Clinic \\ Scripps Memorial Hospital and Research Foundation \\ 9850 Genesee Ave. Suite \#910 \\ La Jolla, California 92037-1220 \\ RobertFoxMD@mac.com \\ http://www.RobertFoxMD.com \\ Julius Birnbaum, M.D/M.H.S \\ Assistant Professor, Division of Rheumatology, Department of Medicine \\ Associate Director, the Jerome Greene Sjogren's Center, \\ Department of Neurology, Bayview Medical Center. \\ 5200 Eastern Avenue, Suite 4100, Room 413 \\ Mason F. Lord Building, Center Tower \\ Baltimore, Maryland 21224 \\ jbirnba2@jhmi.edu
}

\section{ABSTRACT}

This chapter addresses the:

(a) clinical neurological presentation,

(b) laboratory investigation, and

(c) treatment of peripheral and central nervous system disease associated with Sjögren's syndrome.

Peripheral neuropathy has been reported in $10-20 \%$ of patients, mainly in the form of sensorimotor and sensory polyneuropathies. Sub-clinical manifestations may be much more frequent and present in up to $50 \%$ of SS patients.

The severity of symptoms as perceived by the patient may be significantly 
influenced by "central sensitization," i.e., "fibromyalgia."

Central Nervous System (CNS) manifestations of Sjögren's syndrome are diverse, with an array of clinical features including:

- cognitive disorder and neuro-psychiatric manifestations

- transient ischemic attack (TIA) and stroke

- thrombotic manifestations of the brain are more common than large or medium sized vasculitic processes, particularly in association with anticardiolipin and anti-coagulants.

- severe migraine headaches that may mimic TIA with focal weakness after the migraine

- myelopathy including transverse myelitis and demyelinating disease

- gangliopathy

- seizures

- toxi-metabolic encephalopathy

- vasculitis and cranial neuropathies

- Parkinson's disease.

The spectrum of CNS manifestations in SS is generally similar to systemic lupus erythematosus (SLE) patients with the caveat that SS patients have a higher frequency of lymphoproliferative manifestations and the associated neurologic sequellae.

SS patients may also have CNS manifestations caused by secondary factors including infections associated with immunosuppressive therapy, side effects 
from corticosteroids, and occult nutritional deficiencies (resulting from altered eating habits due mouth/dental problems or malabsorption from associated celiac sprue or pernicous anemia).

Treatment. Sensory peripheral neuropathies may respond to pentagabalin or pregabalin.

- Traditional therapies for peripheral sensory neuropathies, such as tricyclic agents amitryptline or nortriptyline, may not be tolerated at therapeutic doses due to their anti-cholinergic side effects.

- The major dose-limiting side affect of antiepileptics--which may lead to premature continuation of these medications-- is aggravation of fatigue, which can be a major cause of subjective morbidity in Sjogren's patients. Such premature discontinuation can be mitigated by slower titration than is normally employed in other patients with neuropathic pain.

- Newer agents such as duloxetene or milnipracin may be useful, particularly in combination with other agents.

- Other causes of neuropathic pain or myelopathy including infections with viruses (ie. Herpes zoster), immmune reactions to viruses (ie. hepatitis C) or spirochetes (including Borrelia species), and mycobacterial infections including tuberculosis must be excluded.

- Other causes of neuropathy including hypertension and diabetes must be carefully controlled and recognition of their exacerbation by corticosteroids, as well as steroid myopathy. 
Corticosteroids are the first-line treatment for myelopathy and vasculitis.

When SS patients fails to improve or deteriorates on corticosteroids, nonsteroidal immunosuppressant(s) should be used for treatment or to help taper the steroid dose:

- Pulse intravenous cyclophosphamide or oral cyclophosphamide is often used for acute vasculitis in SS patients, although controlled trials are lacking .

- Azathioprine, leflunomide and methotrexate may be used to help taper corticosteroids, in a manner similar to systemic lupus or rheumatoid arthritis patients.

- Biologic agents (anti-CD 20, infliximab and anti-CD22 antibodies) have been reported beneficial in small case series of SS patients with neurologic manifestations.

- IV-Ig has been used in axonal polyneuropathies and ganglionopathies that are resistant to corticosteroids and nonsteoridal immunosuppressants

\section{KEYWORDS:}

Sjögren's syndrome, SS

peripheral neuropathy, PNS

central nervous system, CNS

cognitive dysfunction 
polyneuropathy

myopathy

cerebrovascular disease

mononeuritis multiplex

anti-cardiolipin syndrome, $\mathrm{ACL}$

anti-phospholipid antibodies, APS

vasculitis

Fibromyalgia, FMS

Vasculopathy

Cryoglobulinemia

monoclonal gammopathy of unknown significance, MGUS

IgM paraproteinemic neuropathy

demyelinating polyneuropathy

inflammatory demyelinating polyneuropathy, CIPD

dysesthesia

ataxia and Sensory Ataxic Neuropathy

athetosis

areflexia

dysarthria

vasculitic neuropathy

diabetic and non-diabetic radiculoplexus neuropathy

auto-immune autonomic neuropathy

paraneoplastic autonomic neuropathy 
amyloid neuropathy

sporadic amyloid and genetically determined amyloidosis

hypocomplementemia

albumin-cytological dissociation

Aseptic Meningoencephalitis

acute cerebellar ataxia

cerebral venous thrombosis

progressive multi-focal leucoencephalopathy, PML

hypertrophic cranial pachymeningitis

lymphocytic hypohysitis

acute transverse myelitis

neuromyelitis optica (NMO, Devic's syndrome)

\section{BODY TEXT}

\section{INTRODUCTION}

Neurologists occupy an invaluable role in partnering with rheumatologists, to facilitate the diagnosis of Sjogren's patients, to prioritize and interpret diagnostic studies, and help with the management of an eclectic array of CNS and PNS manifestations. There is considerable evidence for the involvement of the nervous system in Sjögren's syndrome (SS)(1). The pathogenic processes include the acquired immune system (T-cell and B-cell mediated factors) and the 
innate immune system (including complement and coagulation systems, as well as release of cytokines/chemokines).

Clinically, there is a very wide range in the reported prevalence of central and peripheral neurological manifestations associated with Sjögren's syndrome. Complaints of peripheral neuropathy, fatigue and impaired cognitive function may occur in up to $70 \%$ of patients and are often listed as the most important clinical extraglandular features in their impaired quality of life assessment (see chapter by Bowman et al).

A wide range of peripheral neuropathies may be found in SS (described further in sections below). These include:

- Small-fiber neuropathies, an exquisitely painful neuropathy which affects unmyelinated nerves

- Axonal polyneuropathies, which can exclusively affect sensory nerves (i.e. axonal sensory neuropathy), which can exclusively affect motor nerves (i.e. axonal motor neuropathy), or which can affect sensory as well as motor nerves (i.e. sensorimotor polyneuropathies).

- Ganglionopathies (i.e. also called sensory neuronopathy or ataxic neuropathies)—loss of proprioception, resulting in "deafferentation", due to dysfunction of the dorsal root ganglia. Such severe deafferentation can cause pseudoathetoid movements, which can be 
misdiagnosed as a movement disorder.

- Vasculitic neuropathies

- Cranial neuropathies (as described below).

- Autonomic neuropathies

Symptoms of muscle or nerve pain (2) may not correlate well with objective testing on standard EMG studies which are most sensitive for large fibers or myelinated A-fibers, in comparison to single unmyelinated C-fibers that serve as nociceptors (3). Dermatomal evoked somatosensory potentials also have a high "false" negative rate in correlations with symptoms (4). Even with newer techniques of skin biopsies stained for nerve fibers, the correlation of symptoms and small fiber changes, the correlation with symptoms may be poor due to the influence of "fibromyalgia" affecting the patient's perception of pain (5).

The differential diagnosis of neuropathies found in SS patients includes those associated with diabetes or hypertension. A diagnostic dilemma is the patient with an "idiopathic neuropathy" and a positive ANA/anti-SS-A antibody. Even though the patient may lack symptoms, signs or biopsies characteristic of SS, these patients may be referred to rheumatology with diagnosis of SS based on the positive ANA for consideration of systemic therapy.

Symptoms of dry mouth and neurological pain are frequent complaint in patients with depression unrelated to SS (6). Again, the laboratory evaluation of these 
patients may reveal a low-titer ANA and raise the question of relationship of their depression and dryness to SS. This group probably includes the common complaint of "burning mouth syndrome" where no other etiology can be ascertained to explain the oral symptoms that appear out of proportion to examination of the oral mucosa or salivary flow measurements. The issue facing the rheumatologist is whether to initiate immunosuppressive therapy or simply pursue symptomatic relief.

\section{Objective abnormalities of the central nervous system (CNS)}

manifestations include both white matter and cerebral atrophy that have been noted in MRI studies and CSF studies of SS patients (7-10). SS patients with transverse myelitis may include relatively distinct subsets that involve the gray and white matter involvement (11), similar to distinct subsets of SLE patients with myelitis(12). The "distinction" of purely anatomic separation of white and gray matter is used here as a simplified way for the rheumatologist to approach this complex diagnostic problem.

Perhaps, the greatest source of debate in the past 20 years has been the incidence of "multiple sclerosis" in SS patients. Initial references reported a relatively high frequency of possible demyelinating lesions on MRI imaging in SS patients with vague symptoms of chronic fatigue. The diagnosis of MS associated with SS led to a great deal of concern on the part of patients and a therapeutic dilemma for physicians. However, using newer MRI techniques 
(described below), the frequency of demyelinating lesions in SS and SLE patients has been reported at less than $5 \%(13,14)$. With the current benefit of the revised MS McDonald criteria (15) — which provides surrogate evidence for dissemination of lesions in space-future studies should characterize the whitematter lesions in Sjogren's patients, through the prism of updated MRI criteria (i.e. Barkhof criteria)(16). Such a comparison would be useful in determining whether the white-matter lesions in Sjogren's patients have the radiographic and morphological features of MS lesions.

Studies in SS have suggested a role for accelerated vasculopathy (particularly in patients with circulating anti-coagulants, leukopenia and elevated CRP) and "atherosclerotic" changes in "precocious" carotid intimal thickening(17). In SLE, accelerated atherosclerosis has been reported on MRI imaging of the brain and correlated with decreased performance on neuropsychiatric testing. It should be noted that one review study failed to find accelerated atherosclerosis in SS patients, in comparison to SLE patients (18). However, as noted in other chapters, the criteria for inclusion of SS patients have varied tremendously over the past decade. Therefore, any "meta-analysis" of studies that assess "early" atherosclerotic CNS changes in SS patients will need to include only SS patients identified by strict current diagnostic criteria. The same factors that lead to accelerated atherosclerosis in SLE are also found in SS patients(17). Therefore, the authors predict that similar processes leading to accelerate vasculopathy will be found to affect the SS patient. Further, attention to preventable factors such 
as "tight control" of blood pressure, lipids and diabetes will be important, as well as control of the underlying inflammatory process that also contributes to vasculopathy.

\section{CLINICAL EVALUATION OF NEUROLOGICAL FINDINGS}

IN SS

It is critical for the rheumatologist to make the following mental notes to guide in the triage of neurological symptoms including:

a. Onset of symptoms and signs (gradual or sudden),

b. Severity and rate of progression of either central or peripheral findings;

c. Distribution as symmetric, asymmetric, proximal, distal, focal or diffuse of peripheral findings;

d. Evidence for co-existence of peripheral vasculitis

e. Evidence for infection associated with onset of central findings (brain or spinal cord).

Although there are exceptions, our experience at Scripps (19) suggests that:

- Seizures and meningo-encephaltiis tend to present acutely and early in the course of disease in association with active vasculitis, similar to that reported in SLE (20);

- Cognitive features due to structural CNS damage tend to develop slowly and later in the course of disease; the contribution chronic fatigue syndrome (i.e. central sensitization, fibromyalgia) makes evaluation of "clinical disability" difficult; 
- CNS manifestations do not closely correlate with peripheral manifestations of active vasculitis or elevation of acute phase reactants such as ESR or CRP;

- Thrombotic lesions in the CNS are more common than large or medium size vasculitis, particularly in patients with circulating anti-coagulants;

-Weakness as an objective presenting sign early in the course of disease may be due to transverse myeltis or CIPD, while myopathy later in the course of disease may result from steroid myopathy;

\section{PATHOGENESIS OF NEUROLOGICAL MANIFESTATIONS}

\section{A. Role of Cell-Mediated Immunity}

Peripheral nervous system involvement in SS was initially thought to be predominantly due to necrotizing vasculitis, similar to that visualized on SLE kidney biopsies or leukocytoclastic skin biopsies (21). However, subsequent studies on biopsies from patients with peripheral neuropathies have found that "true" necrotizing vasculitis of medium or large size blood vessels are uncommon. Instead, a "micro-vasculitis" that has features similar to the peripheral neuropathy of diabetes has (22) been noted in SS biopsies $(21,23)$. These studies have suggested a critical role for lymphocytes and dendritic cells that release cytokines leading to "vasculopathy" that includes complement activation and coagulation pathways (24-26). 
Sural nerve biopsies in a study by Mori et al (22) in Japanese SS patients have demonstrated lymphocytes in the small vessels (including arterioles and high endothelial venules) in association with vascular occlusions suggestive of chronic endothelium damage. Among 55 biopsies from Japanese

SS patients (22), predominantly large fiber loss was observed in sensory ataxic neuropathy, whereas predominantly small fiber loss occurred in painful sensory neuropathy. Angiitis and perivascular cell invasion were seen most frequently in multiple mononeuropathy, followed by sensory ataxic neuropathy. The autopsy findings of one patient with sensory ataxic neuropathy showed severe large sensory neuron loss paralleling to dorsal root and posterior column involvement of the spinal cord, and severe sympathetic neuron loss. Degrees of neuron loss in the dorsal and sympathetic ganglion corresponded to segmental distribution of sensory and sweating impairment. Multifocal T-cell invasion was seen in the dorsal root and sympathetic ganglion, perineurial space and vessel walls in the nerve trunks. Similar changes have been reported in sural nerve biopsies of Caucasian SS patients (27). Biopsies of dorsal root ganglia and autopsy studies of SS patients with CNS manifestations have noted vasculopathy involving the choroid plexus and suggested that alteration of the vascular permeability to antibodies, cytokines and adhesion/entry of either lymphocytes or other proinflammatory cells plays a role (28-30).

Additional studies on sural nerve biopsy of patients with painful sensory neuropathy show reduced density of small diameter myelinated and 
unmyelinated fibers $(31,32)$, in contrast to ataxic neuropathy where large axonal fiber loss is seen $(22,33-35)$. Axonal degeneration is present in teased fiber preparations, without axonal sprouting suggesting dorsal root ganglion pathology.

Epidermal nerve fiber density, as measured by immunostained panaxonal marker protein gene product ("PGP 9.5”)(see chapter by Konttinen et al), is reduced in patients with burning feet- in many cases in a non-length dependent distribution (27).

The number of reported dorsal root ganglion biopsies in sensory ataxic neuropathy is relatively limited $(22,33,34)$ but significant, in terms of the understanding of the pathophysiology. These abnormalities are characterized by T-cell infiltration, neuronal cell and fiber loss, with inflammatory cells around neurons and blood vessels $(35,36)$. Electron microscopy showed "onion bulbs" in one case suggesting prior inflammation $(35,36)$.

Pathological material associated with motor neuropathies in Sjögren's syndrome is restricted to sural nerve and muscle. Sural nerve biopsies show varying degrees of vasculitis of small vessels with decreased fiber density of myelinated axons $(22,33,34)(37-39)$. Perivascular or vascular inflammation in small epineural vessels with necrosis may be seen. Nerve fiber loss may be diffuse or multifocal. 
Terrier et al (39) had eight patients with lymphocytic vasculitis and 14 with necrotizing vasculitis in their 34 patients, noting that vasculitis was present in patients with multiple mononeuropathy and sensorimotor neuropathy, but never in patients with ganglionopathy, and reduced in patients with pronounced sensory symptoms. In the myopathies (40), varying degrees of inflammatory changes occur, in a perivascular, endomysial or perimysial distribution. The majority of infiltrating lymphocytes are T-cells, and inflammatory cells in the perimysium are often associated with a vasculitis (41)(51). Non-specific abnormalities with degeneration, regeneration, muscle fiber size variation, split fibers, atrophic fibers and ragged red fibers are seen as well $(41,42)$.

There appears to be a complex "vicious cycle" that involves humeral immunity described below (including anti-coagulants), innate immune factors such as CRP, complement activation and associated coagulopathy, and cytokine /chemokine release that perpetuates the small vessel damage and leukocyte adherence.

Vasculopathy in the periphery and the CNS is characterized by a small to moderate perivascular accumulation of mononuclear cells, without destruction (e.g., fibrinoid necrosis) of the blood vessel(43). There may be small infarcts due to luminal occlusion. The pathogenic basis of vasculopathy remains largely unknown, but the pathologic findings have some similarity to the biopsies from diabetic patients(43). Indeed, rheumatologists have a great deal to learn about the pathogenesis of SS from the glandular and extraglandular manifestations of 
diabetes(44).

The accessibility of the salivary gland to biopsy may provide a tissue model for understanding the underlying processes that originate with vascular changes and perivascular infiltrates of mononuclear cells and dendritic cells. As outlined in the chapters on salivary gland pathology and neuro-endocrine factors), analysis of the earliest vasculopathy changes in the SS gland may permit understanding of the molecular events that result in vasculopathy. These events include continued activation of the innate immune system that is reflected in type I interferon and interleukin-1 gene signatures found in SS salivary gland tissue biopsies (45), and the later homing of inflammatory cells with resultant metalloproteinase and cytokine induction.

\section{B. The Role of Antibodies Associated with Neurological Manifestations of SS}

The "purest" example of humoral factors in neuro-pathogenesis involves anti-SS A antibodies in pregnant SS patients, where maternal antibodies cross the placenta to interfere with the developing fetal cardiac neural conducting system (46-48). Another example of humoral mediated neuropathic damage is the presence of anti-myelin associated protein in SS patients with chronic inflammatory demyelinated polyneuropathy (CIDP). Anti-cardiolipin antibodies and lupus anti-coagulants predispose to thrombotic events including strokes and microvascular nephritis with hypertensive crises. 
Among differences between SS and SLE, SS patients have a higher frequency than SLE patients of lymphoproliferative disorders including lymphoma.

Accordingly, they have a higher frequency of antibodies associated with mixed cryoglobulinemia (i.e., monoclonal rheumatoid factors that participate in type II mixed cryoglobulin) and other paraneoplastic antibodies such as ANNA-1 or Ri. (49), (50-52) (53).

In these SS patients, the pathogenetic role of autoantibodies in neurological manifestations has been established.

Other autoantibodies have been associated with neurological symptoms but the association may not be causal-

SS patients, in comparison to SLE patients, have a higher frequency of auto antibodies to muscarinic receptors (54) and to fodrin, a structural brain antigen that has been found in circulation after stroke in nonautoimmune patients (55).

These latter antibodies have been proposed to contribute to autonomic and central neurological manifestations, although it is unclear whether the antibodies are pathogenetic or the consequence of neurological damage.

Antibodies from SS patients can be infused into mice to interfere with neural innervation of the glands and the function of bladder smooth muscle of guinea 
pigs or rabbits in vitro. However, the structure of muscarinic receptors in rodents (and their glycosylation) differs from humans. Also, the ability of SS sera to reproducibly react with human cells transfected with muscarinic receptor suggests that the reactivity detected in the bladder muscle assays is not easy to translate to in vivo activity. However, the pathogenetic importance of these antimuscarinic antibodies is potentially very important, since it would change our conception of SS from a SLE-like illness and make it more similar to a myasthenia gravis syndrome, where antibodies against muscarinic receptor are pathogenetic.

\section{INVESTIGATIONS}

\section{Neurophysiology}

Sensory nerve action potentials are often normal, but may be reduced or absent in painful sensory neuropathies and ataxic neuropathy. The presence of preserved Sensory Nerve Action Potentials (SNAPS), in a patient with isolated examination findings of impaired "small-fiber modalities" (i.e. pin-prick and temperature), should immediately suggest the diagnosis of small-fiber neuropathies in SS $(56,57)$. Because the small-fiber neuropathies often affect only the unmyelinated nociceptive nerves, the sensitivity of detection of abnormality is relatively low on routine electrodiagnostic studies. 
Motor nerve conduction abnormalties on EMG/NCV among $28 \%$ of patients were reported in a large cohort study of SS patients from Johns Hopkins University (58); the EMG/NCV most frequently demonstrated predominantly symmetric axonal sensorimotor polyneuropathy, although the patient's symptoms reflected a predominance of sensory symptoms, followed by cranial nerve involvement affecting trigeminal, facial, or cochlear nerves. Multiple mononeuropathy, myositis, and polyradiculoneuropathy were also also reported by these patients. Often, the symptoms preceded the diagnosis of SS. These studies (58) indicated a relatively poorly correlation of motor symptoms and abnormal EMG findings. Similarly, Andonopoulos et al (59) performed EMG/NCV studies on 63 consecutive Greek SS patients with complaints of mild sensory neuropathy. One had pure motor neuropathy and another eight had EMG findings of mixed sensory/motor neuropathy. None volunteered neurological motor complaints. Also, similar results were found in neurologic evaluation and EMG/NCV studies of consecutive Japanese SS patients (57) and European SS patients (60).

Sensory-evoked potentials are often abnormal in ataxic neuropathies $(57,61$, 62). In neuropathies with weakness, compound muscle action potentials are reduced in involved nerves, and sensory nerve action potentials may be affected as well. Motor conduction velocities may be slowed and $\mathrm{F}$ wave latencies prolonged with root involvement $(31,33,60,63)$. 
Neurogenic abnormalities are frequently present on needle electrode examination $(37,38)$. In the myopathies, needle electrode abnormalities are characterized by fibrillation potentials, myopathic motor units and increased recruitment of motor units with muscle activation (table 4).

\title{
Autonomic Studies
}

Heart rate and blood pressure homeostasis in SS patients are often abnormal with tilt table study $(64,65)$. Heart rate and blood pressure variability measurements may be evaluated by several other different methods to evaluate spontaneous baroreflex sensitivity and cardiovascular reflex(66). Segmental anhidrosis may also be noted in SS patients (67).

\begin{abstract}
Abnormal reflex vasoconstrictor responses to contra-lateral cooling can be demonstrated with laser Doppler imaging $(68,69)$. Marked decreases in 123IMIBG uptake cardiac uptake indicating sympathetic innervation abnormalities occur patients with either with sensory ataxic neuropathy or painful sensory neuropathy (57). Thermoregulatory testing (70) may demonstrate abnormalities.
\end{abstract}

\section{MR Imaging of the Spinal Cord}

Spinal cord magnetic resonance imaging may be abnormal in patients with sensory ataxic neuropathy with $\mathrm{T}^{*}$ hyperintensities in the fasciculus cuneatus and gracilis $(57,71,72)$. In one study $(62), \mathrm{MRI}$ abnormalities on $\mathrm{T}^{*}$ of the 
posterior columns correlated with the distribution and severity of the neuropathy. A review of imaging techniques for ganglionopathies in SS patients was recently reported (73).

\section{PERIPHERAL CLINICAL MANIFESTATIONS}

Frequencies of the reported prevalence of neuropathy associated with Sjögren's syndrome vary greatly in different centers, with incidence ranging between 4.5 to $60 \%$ depending on methods of patient selection, population and criteria used for defining Sjögren's syndrome $(33,58,74-77)$.

The clinical expression of the neuropathy associated with Sjögren's syndrome at Scripps (19) (Table 1) is similar to that reported at Johns Hopkins (58) and several other medical centers $(22,33)$.

There are several presentations of peripheral neuropathy associated with Sjögren's syndrome:

- Sensory neuropathies are a common presentation, dominated by either painful dysesthesia or by ataxia

- Motor neuropathy or neuromuscular weakness is the outstanding part of the presentation in other patients, occurring less frequently according to patient's symptoms, but invariably associated with sensory findings. 
- Muscle weakness and pain occur on the basis of direct muscle involvement.

- The autonomic system is frequently involved, often in combination with the other forms, and may be the presenting form as described above including anhydrosis on a neuropathic basis (78).

- Ganglionopathies: An asymmetrical onset can be seen in the ganglionopathies-with initial clinical manifestations including ataxia and dysesthesia—or with the small-fiber neuropathies, in which the distribution of pain can be asymmetrical and multifocal. These neuropathies may involve any distribution-even in a pattern not easily conforming to a dermatomal or neuropathic pattern—involving the trunk, proximal limb, or face.

- Pseudo-athetosis is a continuous stream of slow, sinuous, writhing movements, typically of the hands and feet. This movement, usually of the fingers, occurring when the eyes are closed, caused by a failure of joint position sense (proprioception), for example in peripheral neuropathy. The term is used to distinguish the movements from athetosis, which are caused by damage to the corpus striatum of the brain - specifically to the putamen or caused by a lesion of the motor thalamus.

- Finally, cranial nerves and especially the trigeminal nerve may be affected.

Anhidrosis can present similarly. 


\section{In these neuropathies with a multifocal or asymmetric onset, the"}

neuropathy may evolve into a generalized form, enter a chronic phase, remit or relapse. A gradual onset is more often the case, and the course is frequently mild, but may be particularly severe or disabling, and response to therapy is unpredictable.

\section{PAINFUL SENSORY NEUROPATHIES}

Early case reports describe an asymmetric onset of painful neuropathic symptoms in patients with Sjögren's syndrome $(60,79,80)$. In general, women in their mid-fifties are predominantly affected $(34,57,81)$ often with burning feet being the main complaint. The neuropathy may have a length dependent onset and progress, but early involvement of thigh, hands, trunk or face is not infrequent. Parasthesia may accompany the pain $(37,38)$.

A unilateral presentation with painful dysesthesias spreading to trunk and face chronically over months to years was found in 18 patients $(20 \%)$ without ataxia in one study (34). In this study, 7 patients could not walk because of severe pain. In another study, Kaplan and Schaumberg (82) described a 21-year-old woman with painful left-sided numbness and dysesthesias beginning on the left side of her face, thumb and fore-finger of the left hand, spreading in a week to involve the left arm, mid- forearm and left foot. The neurological abnormalities were confined to the left side with profound loss of vibration and position sense, 
pseudoathetosis and areflexia.

Neuropathic symptoms are usually chronic, may gradually extend, and may be severe.

\section{Differential Diagnosis}

Potential causes of painful small fiber neuropathies include: hypertension, diabetes and "impaired glucose tolerance", alcohol, paraproteins, hyperlipidemia, amyloidosis,Fabry's disease, hereditary sensory neuropathies, drug toxicity including vincristine, paclitaxel and other pharmacological toxins (83-87).

In a study of 124 patients with sensory neuropathy, Devigili et al (87) diagnosed small fiber neuropathy in 67 patients, 5 of whom had Sjögren's syndrome and a sixth developed Sjögren's in the two-year follow-up period.

\section{SENSORY ATAXIC NEUROPATHY}

Sensory ataxic neuropathies occur as a result of pathological involvement of dorsal root ganglia or their axons $(71,88)$.

Malinow et al (36) described a patient with a sub-acute ataxic sensory 
neuropathy and Sjögren's syndrome. This patient developed a band-like tightness around the neck and thorax with pain, dysesthesia and numbness in the left hand, face and tongue, followed by progressive loss of dexterity in both hands, dysarthria and labial anaesthesia.

The examination showed facial numbness, profound loss of position and vibratory sensation in both upper extremities, and moderate loss in the lower extremities. Muscle strength was normal, and deep tendon reflexes were absent. There were pseudo-athetoid movements in both hands and the fingers were hyperextended. Gait was mildly ataxic. Bilateral somatosensory median, radialand ulnar-evoked potentials were absent, but those from the peroneals were present. A thoracic dorsal root ganglion biopsy showed infiltration with mononuclear cells and neuronal degeneration.

The reported frequency of ataxic neuropathy is variable $(33,35,76)$ and was the most commonly occurring presentation in one study (57) with $40 \%$ of patients affected, usually middle aged women.

The onset may be abrupt, slowly progress over years, stabilize or relapse (57, 89). A unilateral presentation is frequent with a variable distribution with loss of proprioception and kinesthetic sensibility and pseudo-athetosis. Autonomic involvement is common (22). 


\section{Differential Diagnosis}

Vasculitis, thrombotic (especially cardiolipin syndrome), embolic, malignant inflammatory sensory polyganglionopathy (associated with antibody to ANNA-1 and ANNA-2, idiopathic non-malignant inflammatory sensory polyganglionopathy (22), toxic sensory polyganglionopathy (pyridoxine, cisplatin, paclitaxe), sensory variant of acute and chronic inflammatory demyelinating neuropathy and IgM paraproteinemic neuropathy are all considerations in the differential diagnosis (89).

\section{NEURO-MUSCULAR WEAKNESS}

From a clinical perspective, one may recognize neuropathies characterized primarily by neuromuscular weakness and categorized as mononeuropathy, multiple mononeuropathy, polyradiculo-neuropathy or sensorimotor neuropathy based on electrophysiological studies.

\section{The distribution of weakness may be segmental, multi-focal, proximal or}

distal and asymmetric. These forms may be associated with varying degrees of sensory involvement, and as a general observation, occur less frequently than the primarily sensory neuropathies. Frequencies and definitions of various types differ $(32,38,39,74,76)$.

There is often an acute onset of weakness together with tingling or dysesthesias 
in a limb distally, extending to a multiple mononeuropathy pattern.

\section{Differential Diagnosis}

Acute inflammatory demyelinating polyneuropathy, chronic inflammatory demyelinating polyneuropathy, non-systemic vasculitic neuropathy, diabetic and non-diabetic radiculoplexus neuropathy and the vasculitides associated with neuropathy are in the differential diagnosis $(89,90)$.

The latter include classic polyarteritis nodosa, mixed connective disease, SLE, overlap syndrome, rheumatoid arthritis and cryoglobulinemic vasculitis. Cryoglobulinemic vasculitis may rarely occur in Sjogren's patients; isolated C4 hypocomplentemia (with normal C3), may be a clue to the presence of a cryogloblin $(91,92)$.

\section{NEURO-MUSCULAR PAIN}

\section{Muscle pain occurs in about one-third (93) of patients with Sjögren's} syndrome, and half of these patients fulfill criteria for Fibromyalgia (94).

Pain affects shoulders, back, thighs and calves, and is usually symmetric and may be associated with weakness. The latter may occur in the absence of pain, and is generally proximal and symmetric in distribution. 
Sjögren's syndrome may be associated with polymyositis, dermatomyositis and inclusion body myositis (95-97). However, the inflammatory changes in muscle do not correlate closely with weakness or pain (41).

\section{Differential Diagnosis}

The main considerations are the inflammatory myopathies including polymyositis, dermatomyositis, including body myopathy, rheumatoid arthritis, mixed connective disease, and scleroderma (40).

\section{AUTONOMIC NEUROPATHY}

Sjögren's syndrome may present with generalized autonomic failure in the absence of other neurological abnormalities.

Sakakibara et al (64) describe a 64-year-old woman presenting with Raynaud's phenomenon followed by painful dry eyes, dry mouth and parotid pain. Three years later, she was constipated; by eight years had postural dizziness; and in ten years, presented to the hospital with decreased perspiration, urinary urgency and decreased frequency of defecation to every fifth day.

Autonomic function tests showed super sensitivity of the pupils to noradrenalin, 
postural hypotension and anhidrosis with provocative testing. Urinary flow was decreased, anal resting pressure was low, and colonic transit time was 144 hours. Motor and sensory nerve conduction studies were normal. There was cardiac super sensitivity to diluted noradrenalin infusion and cardiac denervation on [123I]-MIBG scintigraphy.

Autonomic symptoms may be severe $(22,33)$ with hypotension and syncope as well as widespread anhydrosis, which may be segmental and asymmetric (67). Milder involvement of the autonomic nervous system occurs more frequently (50\% (98), $66 \%$ of those screened (33) and may affect multiple autonomically controlled organs. Orthostatic intolerance, bladder symptoms, constipation, pupillomotor disorder, secretomotor dysfunction, male sexual dysfunction, gastroparesis, diarrhea, sleep dysfunction and reflex syncope are common problems $(33,68-70,99)$.

Parasympathetic nerve dysfunction may be mediated by a deficiency in neural transmission. Bacman and co-workers $(100,101)$ initially demonstrated the ability of antibodies from SS patients to inhibit lacrimal glandular function on transfer into rodents. Wang et al (102) extended these studies by demonstrating that M3 muscarinic receptor-mediated bladder contractions in mice or guinea pig could be blocked in vitro with purified IgG from patients with Sjögren's syndrome. 


\section{Differential Diagnosis}

The differential diagnosis includes acute, sub-acute and chronic autonomic neuropathies $(103,104)$. Post-infectious auto-immune autonomic neuropathy, paraneoplastic autonomic neuropathy, diabetes, amyloid neuropathy in its various forms including sporadic amyloid and genetically determined amyloidosis, drug induced (cis-platinum, vinca alkaloids, and amiodarone) and toxic autonomic neuropathies (heavy metals, hexacarbon compounds and acrylamide) are part of the differential diagnosis. Unusual disorders include hereditary and autonomic neuropathies, porphyria, and distal small fiber neuropathy (104).

\section{TRIGEMINAL NEUROPATHY AND OTHER CRANIAL NEUROPATHIES}

Cranial nerve involvement occurs during the course of Sjögren's syndrome, most frequently involving the trigeminal nerve. Numbness, parasthesia, dysesthesia, altered taste perception are presenting symptoms and motor function is usually spared $(38,57,105)$. Reported prevalence varies $(33,58)$ and may be higher in Japanese patients (74). Other cranial nerve manifestations include hearing loss, vestibular symptoms, facial nerve involvement and loss of olfaction. 
Mori et al reported 5 patients with multiple cranial neuropathies, one with

involvement of cranial nerves III, V, VI, VII, IX, and X, one with bilateral involvement of VII, and recurrent III and VI involvement in one patient $(57,106)$.

\section{CENTRAL NERVOUS SYSTEM MANIFESTATIONS}

\section{There is no unique central nervous system presentation of Sjögren's} syndrome. A broad spectrum of abnormalities have been described, with reported prevalence ranging from $1 \%$ to $46 \%(74,107-110)$.

Presentations include mild cognitive impairment, subcortical dementia, encephalopathy, recurrent aseptic meningitis, seizures, movement disorders, myelitis (including pain, weakness and sphincteric defects), and optic neuropathy with relapsing and remitting features similar to multiple sclerosis $(74,107-110)$.

While given episodes can be transient and self-limited, there is generally progressive disease with cumulative neurological impairment (107).

Central nervous system inflammatory disease, cognitive disorders, movement disorders and meningoencephalitis are described in more detail.

\section{A. Central Nervous System Inflammatory Disease}


Myelitis is a devastating inflammatory syndrome of the spinal cord causing weakness, numbness and sphincteric deficits. It has frequency of approximately $5 \%$ in SS patients in the Johns Hopkin's cohort, which is more than a thousandfold greater than idopathic myelitis in the general population (111). The frequency and features appear similar to those recently reported in a cohort of SLE patients with myelitis from the same institution, in which two distinct syndromes could be distinguished clinically by involvement of the central gray or the outer white matter neural tracts (111). It is recognized that the Johns Hopkin's experience (and other reported series referenced below) represents the referral bias of much sicker patients to a tertiary institution.

Patients with gray matter dysfunction (i.e., spasticity and hyperreflexia) were more likely to present with fever and urinary retention. These patients were more likely to present with high systemic activity of their underlying SLE (111). Their CSF profile was similar to bacterial meningitis and they were more likely to have irreversible paraplegia. Patients with white matter dysfunction were also more likely to meet criteria for neuromyelitis optic (NMO, Devic's syndrome) and were more likely to have anti-phospholipid antibodies (111). The actual "anatomic distinctions" between gray matter and white matter involvement are actually much more intricate, but this simplification is provided to help rheumatologists recognize and categorize clinical patterns in SS patients.

Optic neuritis was seen in about $50 \%$ of the NMO patients and they had a 
characteristic anti-NMO antibody, which predicted an increased chance of relapse. A paradoxical finding was that spinal cord MRl's showing postgadolinium enhancement was seen more frequently in patients with white matter myelitis, despite the tendency of white matter myelitis to occur with less severe inflammatory and CSF findings. This was attributed to the swelling of the spinal cord and progressive venous hypertension that decreased perfusion between the spinal radicular arteries and the pial venous plexus. Thus, the same compromised blood flow to the gray matter tracts also limited efflux of the gadolinium (111).

Multiple sclerosis is an inflammatory disease of the nervous system for which no test is pathognomonic (15). There has been debate over the past two decades over the frequency of this complication in SS patients.

Histopathological studies of demyelinated lesions show considerable heterogeneity at the cellular and molecular level thought to be related to the diversity of the clinical presentation (112).

In 1986, Alexander et al described 20 patients with primary Sjögren's syndrome with features indistinguishable from multiple sclerosis (107). Ataxia, visual loss, hypesthesia, hemiparesis were frequent occurrences, and the course was relapsing and remitting course or progressive, with frequent spinal cord involvement. 


\section{Important differences from the usual presentation of multiple sclerosis}

were vasculitis on biopsy of skin or muscle with a predominantly mononuclear vasculopathy and reduced number of oligiclonal bands in cerebrospinal fluid that decreased sequentially with corticosteroid therapy. It was thought that CNS Sjögren's syndrome was an auto-immune inflammatory ischemic small-vessel cerebral vasculopathy affecting sub-cortical and periventricular white matter.

Based on these findings, a higher prevalence of Sjögren's syndrome-associated nervous system inflammatory disease would be expected (113-115), but has not been confirmed, with the exception of in Asia, where MS is rare (116).

In primary progressive multiple sclerosis-like syndromes with myelopathy, the association with Sjögren's syndrome is stronger (117). However, the association of MS and SS is controversial, particularly in patients lacking antibodies to ANA (118).

A case described by Tsai, Tsai and Liao (119) summarizes the problem of distinguishing Sjögren's syndrome associated with CNS inflammatory disease from multiple sclerosis:

A-27-year-old woman developed diplopia and ataxia, which subsided after 10 days. Over the next 15 months, she had 6 discreet neurological episodes 
associated with T2 hyperintensities on MRI of the brain. These included left optic neuritis, lower extremity numbness, leg numbness and neurogenic bladder, right optic neuritis, left leg weakness, and left facial palsy. Betaseron was started after the third episode. Each episode responded to high-dose steroids with the exception of the sixth episode that left her with paraparesis.

A month after the sixth attack, she developed diplopia, exacerbation of leg weakness, dry eyes and dry mouth.

Sjögren's syndrome was diagnosed on the basis of a positive Schirmer's test, Grade IV changes on labial salivary gland biopsy, and xerostomia on sialoscintigraphy.

She was again treated with pulse therapy, this time followed by $60 \mathrm{mg}$ daily of prednisone, which was tapered to $30 \mathrm{mg}$ per day, with no relapse in 12 months.

The pathological basis for inflammatory central nervous system disease in Sjögren's syndrome has not been established. The underlying abnormality is thought to be intracranial vasculitis or vasculopathy (105).

Moore and Lisak long ago thought alternative diagnoses should be considered in multiple sclerosis until tests to unequivocally define multiple sclerosis and Sjögren's syndrome become available. 


\section{B. Cognitive Impairment}

Cognitive impairment-- characterized by inattention, poor concentration, memory impairment and loss of verbal fluency is frequently reported by patients with Sjögren's syndrome or demonstrated with neuropsychological testing $(109,120)$. Psychometric studies may show impairments of visual memory, reduced perceptual speed and loss of fluid intelligence (110).

The clinical presentation may be characteristic of subcortical dementia (58), and Alzheimer-type dementia, and a frontal lobe syndrome has been described (121).

Two case descriptions illustrate the range and chronicity of the dementia in Sjögren's syndrome:

Kawashima described a patient with subcortical dementia (122). This 48-yearold male schoolteacher developed lassitude, forgetfulness and withdrawal over 6 months. The first symptom was a poorly delivered speech.

On examination he was oriented, inactive, irritable, slow, hostile and circumferential. An MRI demonstrated ventricular dilatation and T2 periventricular hyperintensities. His verbal IQ was 82 and performance IQ was 66 . 
After treatment with prednisone, he became active, reasonable and cooperative, His neurological condition worsened with tapering steroids, but improved with resumption of therapy.

Caselli et al described a case of reversible dementia in a 56-year-old woman with a 16-year history of Sjögren's syndrome who lost the ability to program her computer (123). There was spontaneous improvement after 6 months, and 18 months later, she developed visual hallucinations, and started hiding her medications.

Magnetic resonance imaging, cerebral angiography and spinal fluid examinations were all normal. Alzheimer's disease was diagnosed and she continued to deteriorate. Fifteen months later, she was readmitted to the hospital with perseveration, phonemic errors and memory impairment.

MRI of the brain and carotid angiography were again normal, but cerebrospinal fluid showed an elevated protein with 1 oligoclonal band. A right prefrontal brain biopsy revealed lymphocytic perivascular leptomeningeal and rare intraparenchymal infiltration. Gliosis was seen in superficial cortical layers, but there were no areas of microinfarction, viral inclusions, and neurofibrillary tangles, or amyloid plaques. Focal vascular wall infiltration was present, but no transmural vasculitis. 
She was initially treated with120 mg oral prednisone per day (tapered in 3 months to $25 \mathrm{mg}$ daily) and made a dramatic clinical improvement returning to nearly normal, according to family.

An abnormality of brain muscarinic acetylcholine receptor function and regulation may be responsible for the cognitive abnormalities seen in Sjögren's syndrome. Orman et al purified IgG from 15 patients with primary Sjögren's disease that were positive for anti-M1 and anti-M3 activity (124).

All patients had a frontal lobe disorder on neurospsychological testing. They showed that pSS IgG evoked nitric oxide synthase and prostaglandin E2 production from rat cerebral cortex. NOS in other systems has been associated with cell death $(125,126)$.

\section{Movement Disorders}

Parkinsonism and other movement disorders are generally degenerative or genetically determined, but there is evidence (127-132) that when associated with Sjögren's syndrome, the movement disorder may be driven by an immune mechanism. Distinguishing features are lack of response to dopaminergic drugs, improvement with steroids, and diffuse periventricular T2 hyperintensites on brain MRI. 
Nishimura et al described a 74-year-old woman with a 10-year history of primary Sjögren's syndrome who developed parkinsonism that was responsive to steroids (130).

The initial presentation was with a short steppage gait non-responsive to dopaminergic therapy. The gait deteriorated over the next 7 years with hesitation, festination, freezing, akinesia and rigidity. MRI showed T2-weighted hyperintensities in deep white matter and basal ganglia.

Following the administration of $30 \mathrm{mg}$ of prednisone daily, there was a brisk improvement in gait and bradykinesia, the sedimentation rate dropped from 106 to $20 \mathrm{~mm} / \mathrm{hr}$, and MRI abnormalities decreased in size.

Other movement disorders associated with Sjögren's syndrome respond to steroids, although not invariably $(133,134)$.

Papgeorgiou et al reported a 57-year-old woman with a 2-year history of Sjögren's syndrome, who had involuntary muscle contractions around the mouth and eyes, progressing to face and neck that was diagnosed with orofacial dystonia (134).

She was non-responsive to dopamine, clonazapam, and levetiracetam, but after $1 \mathrm{~g}$ of methylprednisilone IV for 3 days followed by prednisone, the patient 
experienced a dramatic improvement, and was virtually symptom-free in 2 months.

Similarly, Fanchke et al describe a 43-year-old woman with Sjögren's syndrome presenting with generalized choreic movements of the axial skeleton and face followed by depression and cognitive impairment that improved with steroids and azathioprine (133).

Elevated titers of anti-beta2-glycoprotein I IgG (127) have been found in 3 patients with Sjögren's syndrome and Parkinson's disease. Purified alpha-beta2 glycoprotein antibodies bind to cerebral endothelial cells, suggesting an immune mediated vascular etiology.

\section{Aseptic Meningoencephalitis}

Aseptic meningitis and meningoencephalitis have been described in patients with Sjögren's syndrome, often characterized by pleiocytosis, protein elevation and increased lgG synthesis rate in spinal fluid.

In some instances there is vasculitis on biopsy of muscle and skin. These disorders may be recurrent, associated with other neurological abnormalities including seizures, cranial nerve palsies and coma, and respond to steroids (135140). 
A fatal case of meningoencephalitis, upon autopsy, was described by Gerraty et al on an 18-year-old patient who initially presented with fever, somnolence and seizures (141). Findings had included positive sialography, anti-SSA and SS-B antibodies, 62 lymphocytes on CSF examination with protein $0.34 \mathrm{~g} / \mathrm{dl}$ and the patient was treated with prednisone $0.5 \mathrm{mg}$ daily followed by Cytoxan with no improvement.

She had responded markedly to plasmapharesis. A brain CT scan showed several small infarctions in the temporal and parietal lobes. She had memory impairment and frequent focal and generalized seizures.

The illness was protracted, but after 3 months, she had developed increased drowsiness that did not respond to plasmapharesis, and she expired 6 months after that initial hospital admission. Laminar necrosis of the frontal and parieta cortex was seen on autopsy together with small infarcts but no vasculitis.

\section{E. Other Neurological Disorders}

Various other unusual neurological syndromes occur during the course of Sjögren's syndrome. Syndromes include epilepsy (142), acute cerebellar ataxia (143), cerebral venous thrombosis (106), and progressive multi-focal leucoencephalopathy (144). 
Li et al described a case of hypertrophic cranial pachymeningitis and lymphocytic hypohysitis in a 74-year-old with Sjögren's syndrome (145). The original presentation was headache, dizziness and general malaise with polydipsia and polyuria. CSF was negative, and MRI showed thickened meninges with gadolinium enhancement, mildly enlarged pituitary gland, and thickening of the pituitary stalk with extension along the basal hypothalamus.

Hypopituitarism was evident on endocrine study. MRI thickening of the dura was reduced with steroid therapy. Biopsy of dura mater 4 months later showed an inflammatory response characterized by patchy infiltration of small lymphocytes, and plasma cells, fibrosis hyalinized collagen tissue. There was no vasculitis. The cells were predominantly CD3+ lymphocytes.

Niemela et al describe a 24-year-old with primary Sjögren's syndrome and grand mal seizures (142). This patient had a past history of arthralgia, fever and Raynaud's phenomenon, and developed a confusional state and grand mal seizures. The cerebrospinal fluid had a protein $5000 \mathrm{mg} / \mathrm{L}$, with $5 \mathrm{WBC}$.

Initial treatment with prednisone was ineffective, and the patient deteriorated became somnolent, but responded to pain with eye opening. Cyclophospmide $15 \mathrm{mg} / \mathrm{Kg}$ on days $0,8,29,50$ resulted in improvement. The patient became oriented, walked in 3 weeks, and was normal cognitively in a year. 


\section{INVESTIGATIONS OF CENTRAL NERVOUS SYSTEM MANIFESTATIONS}

\section{Serology}

Serum anti-SSA and less frequently anti-SSB antibodies are present in patients with CNS disease and SS, more so with focal disease and when angiographic abnormalities are present $(58,146)$. The patient's sera should also be tested for circulating anti-coagulants (anti-cardiolipin and/or anti-phopholipid antibody, lupus anti-coagulant) and RPR/FTA. There have been some reports of association with antibody to ribosomal P protein $(147,148)$ [Ghirardello, 2000 \#16\} and to neuronal antigens (149-151) associated with neuro-psychiatric manifestations. However, these assays have not been sufficiently replicated to advocate their use at present time. More recently, Alpha-fodrin antibodies have been proposed to distinguish primary progressive multiple sclerosis from Sjögren's syndrome (97). Again, confirmatory studies will be required.

Additional serologic abnormalities have been associated, including a higher prevalence of

- C reactive protein $68 \%$ vs. $6 \%$

- RF $76 \%$ vs. $35 \%$

- hypocomplementemia $56 \%$ vs. $19 \%$

- monoclonal gammopathy $36 \%$ vs. $6 \%$

- SSA/ Ro $77 \%$ vs. $50 \%$

- SSB/La $55 \%$ vs. $28 \%$, and 
- increased serum beta2 microglobulin

in patients with vasculitis have been observed in some presentations [Terrier, $2007 \# 112]$.

\section{Spinal Fluid}

Spinal fluid examination, when performed, has shown protein elevation in a small proportion of cases of painful neuropathy and ataxic neuropathy, and pleiocytosis may occur in ataxic neuropathy (33). Albumin-cytological dissociation on spinal fluid examination has been described (33).

Pleiocytosis, elevated protein, inceased IgG synthesis rate and oligoclonal bands occur during the course of central nervous system disease in Sjögren's syndrome $(152,153)$. Anti-SSA and SSB antibodies have also been found in the CSF in some cases with evidence of increased intrathecal synthesis of anti-SSA auto-antibody (154).

\section{MRI Imaging}

\section{Both white matter and cerebral atrophy have been noted in MRI studies of}

SS patients. Recent technological advances in MRI imaging using tensor imaging (DTI) may make possible more detailed imaging to correlate brain tissue integrity and volume loss in SS patients and SLE patients $(13,14)$. The higher 
resolution MRl's indicated that the previous studies were identifying vascular lacuni rather than demyelinating lesions (9). These studies have shown an incidence of demyelinating lesions less than $5 \%$, in contrast to the characteristic alterations found in well characterized multiple sclerosis patients.

T2 weighted hyperintensities on brain MRI abnormalities are seen in SS affecting white and gray matter in periventricular or subcortical regions (8). Frontal and parietal lobes are commonly involved and abnormalities in general may correlate with focal neurological signs (155).

MRI abnormalities are non-specific and T2 hyperintensities may represent edema, gliosis, demyelination or axonal loss (156). The prevalence of cerebral MRI abnormalities varies in primary Sjögren's syndrome populations and is higher in patients with neurological impairment (156).

\section{Nuclear Brain Imaging Studies}

Cerebral blood flow measured with Technetium-99m-HMPAO SPECT and glucose metabolism measured with FDG-PET in patients with Sjögren's syndrome with neuropsychiatric symptoms including cognitive and memory impairment are frequently abnormal (120).

MRI brain scans may be normal in these cases. Researchers have found multiple 
areas of hypoperfusion, usually bilateral, in cortex and basal ganglia (157-159).

\section{Cerebral Angiography}

There are limited reports of cerebral angiography in Sjögren's syndrome.

Alexander et al reported on 45 patients with Sjögren's syndrome who had cerebral angiography for clinical reasons (146). Twenty had abnormal studies, of which 18 had radiographic findings of stenosis, dilatation or occlusion of small cerebral blood vessels consistent, with small vessel angiitis. Small arteries of the anterior and posterior circulation were involved. 4 patients had involvement of medium size or larger vessels. 5 patients had 1 or more aneurysms.

\section{THE PUZZLING NEUROLOGICAL MANIFESTATIONS OF FIBROMYALGIA}

Perhaps the most common clinical problem in the SS patient is vague cognitive dysfunction and diffuse myalgia (Fibromyalgia). These problems are more difficult to assess as a consequence of the immune process as there are few clinically available objective tests. However, the frequency of Fibromyalgia in SS patients is higher than the general population, and these complaints often overwhelm other aspects of the patient's (or physician's) global assessment of quality of life and the patient's disability (see chapter on Fibromyalgia).

However, the problem of Fibromyalgia (i.e., central pain sensitization) often has 
less obvious consequences than simply unexplained fatigue. The severity of pain or weakness reported is often out of proportion to observed clinical, EMG/NCV or biopsy findings. It is difficult to know if these "amplifications" of pain result at the level of the dorsal root ganglia, the ascending/descending channels of the spinal cord or in particular regions of the brain. It is not known if they result from an inflammatory process or a vasculopathy.

The high frequency of "Fibromyalgia" symptoms in the SS patient is the "elephant in our diagnostic exam room," as these patients frequently complain of disabling pain or fatigue.

Among primary care physicians, there is little recognition of the lack of specificity of low-titer ANA and the relatively high frequency of "false positive" results(160, 161). This leads many primary care physicians to refer Fibromyalgia patients with a low titer ANA to a rheumatologist to "rule out" autoimmune disorders such as SS.

On the other hand, a neurologist may perform an extensive workup of peripheral neuropathy including nerve biopsy while evaluating an "idiopathic" neuropathy. If a positive ANA is noted, the patient often is often termed SS even if the patient lacks dry eyes/mouth or other criteria for SS.

\section{INTERPRETATION OF ANTI-NUCLEAR ANTIBODY (ANA) IN}




\section{THE PATIENT WITH NEUROLOGICAL SYMPTOMS}

Another area of diagnostic confusion is the anti-nuclear antibody (ANA). There is a misconception that a positive ANA (singularly) "makes" the diagnosis of SLE or SS.

The ANA is used to confirm the diagnosis, and the test done by immune fluorescent method (IFA) is more sensitive than it is specific (161). The test shows variability in different laboratories and the ELISA test has many more false negatives (162) than the IFA method and may lead to missed or incorrect diagnosis as illustrated in a recent clinical pathologic conference published in New England Journal of Medicine (163).

The frequency of patients with a low titer ANA increases with age (164). Patients with Alzheimer's disease frequently have increased oral and ocular dryness complaints due to impairment of cortical white matter outflow, autonomic neuropathy, and changes in nerve growth factor as well as the normal atrophy of secretory glands that occurs with age (70). Indeed, the basis of several approved drugs for Alzheimer's disease such as rivastatin is based on their cholinergic stimutory activity(165). Thus, the presence of a low-titer ANA in an older patient may lead to a clinical diagnosis of SS, even when the salivary gland biopsies are normal or show expected age-related atrophy. 


\section{TREATMENT}

\section{A. Peripheral Nervous System Treatment: Overview}

There are no controlled clinical trials of treatment for the neuropathy of Sjögren's syndrome. Multiple immune-based therapies have been to shown to be effective in many isolated cases based on individual case reports and several series of patients.

Our approach to therapy is largely based on our experience with treatment in SLE patients with central and peripheral neuropathy. Treatment has included corticosteroids, cyclophosphamide, intravenous gammaglobulin, plasma exchange, D-penicillamine, chlorambucil, rituximab and infliximab $(56,166-173)$.

Few treatments of acute neurological syndromes are "controlled trials." Symptomatic treatment of painful neuropathies generally follows the guidelines used for treatment of diabetic neuropathies. However, the anti-cholinergic side effects of tricyclic agents make these agents poorly tolerated in SS patients.

Immune mechanisms are not necessarily the same in the various forms of neuropathy (116), and there may be marked differences in rates of favorable responses between the various neuropathic forms (9) (table 6). 


\section{B. Painful Sensory Neuropathies}

Kizawa et al report a favorable response to IVIG in a patient with Sjögren's syndrome with severe sensory symptoms such that he could not open his hands and walk, with a recurrent episode 6 months later responding to the same treatment (174).

Coroyer et al describe a 68-year-old woman with Sjögren's syndrome who developed distal tingling and burning in both hands who responded to a course of infliximab (166).

Grant and Dyck reported treating sensory neuropathy with steroids, IVIG and plasmapharesis and found the response to treatment was equivocal and recommended controlled clinical trials to establish effective therapy (174).

\section{Ataxic Neuropathy}

Chen et al describe 4 patients with Sjögren's syndrome (one of whom had SLE) and ataxic sensory neuropathy treated with 5-9 plasma exchanges (170). The two patients who had acute onset of symptoms responded to this therapy.

Takahashi et al and others have shown a functional benefit of IVIg in longstanding severe ataxic neuropathy, where prior steroids and plasmapharesis had 
failed, and noted the rapid improvement and long-lasting effect in spite of longstanding chronic disability(109). In IVIg-dependant neuropathy, ritaximab may be effective (168). Cyclophosphamide (56) and D-penicillamine (172) have also been reported as beneficial in this neuropathy.

\section{Motor and Sensory Neuropathy}

Mori et al thought corticosteroid therapy was likely to be effective for multiple mononeuropathy (22).

Terrier et al (39) treated 40 highly selected patients with Sjögren's syndrome where neuromuscular biopsy was one of the inclusion criteria, with corticosteroids (38 patients), azathioprine (8 patients), cyclophosphamide (10 patients), hydroxychloroquine (3 patients), rituximab plus cyclophosphamide (1

patient), methotrexate (1 patient), CHOP (1 patient) and plasma exchange (4 patients). They found a good response in 12 of 40 patients, moderate response in 9 of 40, stabilization in 17 of 40 , worsening in 2 of 40 and relapse in 19 of 40 .

\section{E. Central Nervous System Treatment}

As with peripheral nervous system involvement in Sjögren's syndrome randomized blinded placebo-controlled studies are not available. In addition there is a lack of precise knowledge regarding the underlying pathogenesis (174). 
Treatment is based on case reports and several case studies. Steroids are frequently effective in CNS Sjögren's $(36,175)$. In progressive focal CNS destruction, monthly intravenous cyclophosphamide for 12 months until stabilization or improvement seen has been recommended (176). Cyclophosphamide has also been recommended in treatment of myelopathy $(177,178)$.

Combination therapy with steroids and cyclophosphamide improved EDSS and ambulation in some patients with myelopathy (117). Steroids and chlorambucil were effective in another instance (179).

There is one case report each of the use of rituximab, IVIg and plasma exchange:

Yamout et al describe a 47-year-old woman with recurrent weakness of the lower extremities due to an extensive demyelinating lesion T7-T10 that improved with rituximab after steroids and cyclophosphamide failed (180). She had become bedridden, but returned to daily activities in 8 months.

Canhao et al describe a 67-year-old woman diagnosed at age 50 with Sjögren's 
syndrome who developed recurrent ataxia and dysmetria, controlled with prednisone and cyclophosphamide for 3 years, at which point she worsened with confusion dysarthria and ataxia (181). IVlg $400 \mathrm{mg} / \mathrm{Kg} /$ day for 5 days resulted in a dramatic response of neurological symptoms, and recurrent relapses have remained responsive to this therapy.

Konttinen et al describe a 54-year-old woman with a 2-year history of Sjögren's syndrome, who developed myalgias followed by internuclear opthalmoplegia, acute transverse myelitis at T6 with complete paraparesis, urinary retention and fecal incontinence (182). Visual evoked potentials and MRI of the brain were normal. Prednisone was started at the onset of paraparesis, and plasma exchange 6 days later. The first signs of improvement were within a week. She could stand with a tilt table at 6 weeks, had normal urination at that point, and at about 3 months, could walk with a 4-point cane.

\section{F. Side effects of immunosuppressive therapy}

Relatively little has been reported about the side effects of steroidal or nonsteroidal complications in SS patients, in contrast to larger studies focusing on SLE. The side effects of traditional therapies including oral and pulse cyclophosphamide, azathioprine and cyclosporin A in SS patients have been recently reviewed by Mavragani et al (183), who also has updated this topic in another chapter of this textbook. The problems of immune suppression and bone marrow toxicity with cyclophosphamide are similar to SLE patients (183). Also, pneumonitis may reflect opportunistic infections including pneumocystic or 
"drug pneumonitis" such as "alkylator lung." These findings may present diagnostic dilemmas due to the relative high frequency of leukopenia and/or thrombocytopenia as a result of the SS pathogenesis. Similarly, the increase in chest xray infiltrates may be due to the SS pneumonitis or infections. The problem is particularly difficult in treating neurologic problems, where side effects including PML (progressive multifocal leukoencephalopathy) may occur in SS patients in the absence of immune suppressive therapy (144) and has been recently associated with certain biologic agents such as rituximab (although at very low rates). Corticosteroids may have the effect of acceleration of dental decay, in addition to the side effects of osteoporosis, avascular necrosis, glaucoma, diabetes and steroid myopathy.

\section{Summary of Special points to neurologists}

Neuropathic pain in Sjogren's patients.

The management of neuropathic pain in Sjogren's patients may be especially challenging. The normal therapeutic armamentarium, which may be useful in other subgroups of patients with neuropathic pain, may present unique iatrogenic difficulties in Sjogren's patients. However, by working with Sjogren's patients to modulate expectations and anticipating such side effects, neurologists can facilitate the symptomatic manifestations of neuropathic pain.

The use of tricylic antidepressants (TCAs) remains first-line agents in the treatment of neuropathic pain. Because of the anticholinergic side effects, which may aggravate sicca symptoms, they are often regarded as contraindicative in Sjogren's patients. However, some Sjogren's patients with milder sicca manifestations may be able to tolerate nortryptilline. In contrast, to amitryptilline--which is a tertiary amine-nortryptilline causes less anticholinergic side effects. Therefore, slow titration of nortryptilline may be useful. 
The institution of neuropathic agents such as Neurontin and/or Lyrica is often attempted and abandoned, because of the exacerbation of fatigue, which may be an especially prominent symptom in Sjogren's patients. As for the use of TCAs, patients should be counseled that often the sedative effects of these agents habituate with time. Again, slow titration of agents towards doses, which are effective in therapeutic trials, may be necessary.

Neurologists should also be aware that Sjogren's patients might employ an imaginative, varied, and graphic description of neuropathic pain, with a nosology, which is sharply different from traditional descriptors of neuropathic pain. For example, neuropathic pain may be described as occurring in distributions not conforming to dermatomes, or the distributions of peripheral nerves. There are several reasons why pain may not crisply conform to such orthodox boundaries. First, in patients with small-fiber neuropathies, more than 50 percent of Sjogren's patients may experience pain in proximal as opposed to distal regions-i.e. disproportionately affecting the thighs versus the toes. In other scenarios, pain may be described as exquisite sensitivity, in virtually all regions of the torso. Such diffuse tenderness to palpation-which is termed as dynamic touch allodynia in many neuropathic pain questionnaires---may be due to the "central" sensitization of neuropathic pain. The term "central" sensitization of neuropathic pain refers to the constellation of changes which may amplify neuropathic pain, due to hyper excitability of ion channels in the Dorsal Root Ganglia (DRGs) and the spinal cord, morphologic changes of cellular elements, and cytokine changes which may render "gating" of somatosensory cues intractable to central, inhibitory pathways (i.e. the GABA pathway). Therefore, the experiential features of "central" sensitization of neuropathic pain can be indistinguishable from fibromyalgia.

Whether fibromyalgia should be regarded as "central" neuropathic pain is currently controversial. Nevertheless, when neurologists are confronted with touch allodynia--- which may not crisply conform to traditional neuoranatomic boundaries, the SNRIS medications (i.e. Cymbalta) may be useful

In addition to recognizing the unorthdox and heterogeneous descriptors of neuropathic pain, there may be concomitant causes of pain which often go overlooked, but which may be amplifying the experience of neuropathic pain. Overweight patients who complain of fibromyalgia may have sleep apnea; therefore, screening by sleep studies is important. Other comorbid conditions may include hypothyroidism, adrenal insufficiency, and depression

Demyelinating syndromes in Sjogren's patients

The sinuous relationship of Multiple Sclerosis (MS) has been described above, with discrepant attributions reported by different authors When 
demyelinating episodes occur in Sjogren's patients, there is often a dilemma about whether the operative diagnosis should be Multiple Sclerosis (MS), or a demyelinating syndrome due to Sjogren's syndrome. This dilemma is not only important as a ritualistic, nosological debate-but has dramatic therapeutic repercussions. Specifically, the interferon-based medications, which are useful in reducing new clinical attacks and brain lesions in MS, have been amply reported as potentiating or aggravating systemic rheumatic diseases. Therefore, neurologists can play a crucial role in directing rheumatologists towards the appropriate diagnosis and treatment

First, neurologists should alert rheumatologists that not all demyelinating episodes are due to MS. In the past five years, there is increasing recognition that the demyelinating episodes constitute a heterogeneous group of disorders, with distinguishing clinical, radiographic, and serological features. For example, Neuromyelitis Optica/NMO can occur in patients with systemic rheumatic syndromes, including systemic lupus erythematosus (SLE), and Sjogren's syndrome

A common source of consternation---for both neurologists as well as rheumatologist-is that the radiologists' interpretation of white-matter lesions in Sjogren's patients have an unwieldy cornucopia of causes, ranging from "vasculitis" to "MS", to the diathesis of Sjogren's". However, a few principles should apply. First, CNS vasculitis is the rarest of the vasculitides, and will likely never be the cause of such lesions. Second, neurologists can now apply the Barkhof MRI criteria, which have been incorporated into the revised 2005 McDonald diagnostic criteria for MS. The McDonald criteria incorporate the Barkhof criteria to serve as a MRI surrogate for the clinical requirement of lesions which may be "disseminated in space" The neurologist's meticulous application of the Barkhof criteria, may demonstrate to rheumatologists that the distribution and morphologic features of such white-matter lesions are inconsistent with MS. It is highly likely that earlier reports in the 1980s attesting to the frequency of "MS" in Sjogren's patients, did not have the benefit of utilizing such radiographic criteria

The potential mechanisms of white-matter lesions not satisfying the Barkhof criteria are uncertain, and have been reviewed earlier in this chapter.

Relationship of neurological symptoms to sicca manifestations

Both the Central Nervous System (CNS) and Peripheral Nervous System (PNS) manifestations may antedate emergence of glandular symptoms in up to 50 percent of Sjogren's patients, sometimes by up to a decade. Even in the absence of prominent sicca symptoms, neurologists should be especially vigilant for potential emergence of Sjogren's symptoms, especially when encountering 
neuropsychiatric manifestations, which may be prototypical of Sjogren's patients. Examples of such prototypical PNS manifestations would be the larger-fiber ganglionopathies/sensory neuronopathies, or small-fiber neuropathies not occurring in a length-dependent gradient. In some scenarios, there may be subtle symptoms of xerostomia and keratoconjunctivitis sicca, but such "glandular" manifestations may be overlooked in the context of devastating neuropsychiatric disease. Examples of prototypical CNS manifestations would include opticospinal manifestations occurring in the context of Neuromyelitis Optica/NMO (see below), or demyelinating episodes not satisfying diagnostic criteria for Multiple Sclerosis (MS)

Therefore, neurologists must ruthlessly query and pursue even the subtlest manifestations of sicca symptoms. It is not sufficient to merely ask patients, "Do you have dry eyes or dry mouth?". The symptomatic manifestations of keratoconjunctivitis sicca are protean: patients should be asked about sensitivity to light, about inability to wear contact lenses. Similarly, the manifestation of xerostomia may be unearthed by an increased burden of caries, or by complaints halitosis. In female patients, incipient sicca symptoms may be heralded by vaginal dryness: patients should be asked about recurrent candidiasis, or dyspareneuria.

In other scenarios, even a meticulous assessment for subtle sicca manifestations may not suggest the glandular manifestations of Sjogren's syndrome. Although such patients may be provisionally relegated as having "idiopathic" neuropsychiatric syndromes, there should be hypervigilant suspicion on longitudinal evaluation, for eventual emergence of any glandular manifestations.

Lastly, neurologists should be aware that the current American-European classification criteria allow for the diagnosis of Sjogren's' syndrome-even when patients lack symptoms of dry eyes or dry mouth. In such scenarios, the diagnosis is facilitated by both demonstration of sialadenitis on lip biopsy, as well as seropositivity to anti-Ro/SS-A and/or anti-La/SS-B autoantibodies, along with at least one "functional" test, which may corroborate subclinical sicca symptoms. Therefore, we recommend that when patients without sicca symptoms, present with the above prototypical PNS or CNS manifestations which are suggestive of Sjogren's syndrome, that lip biopsy be performed when there is seropositivity to anti-Ro/SS-A or anti-La/SS-B autoantibodies.

In summary, the neurologist may play a crucial and gratifying role in diagnosing Sjogren's syndrome, by limning the expertise to recognize neuropsychiatric manifestations, which may be the "footprint" of Sjogren's disease, even in the absence of sicca symptoms.

\section{SUMMARY FOR RHEUMATOLOGISTS}


Sjögren's syndrome has a wide variety of neurological manifestations ranging from peripheral to central signs and symptoms. The neurologic symptoms are a key reason for extraglandular morbitidy in SS and patient's assessment in their "quality of life".

The symptoms of peripheral neuropathy are common and correlate poorly with EMG measurements due to involvement of unmyelinated nerves. Also, the severity of symptoms is affected by the presence of "fibromyalgia" that may amplify "pain" signals at the level of the spinal cord or CNS. Evidence for immune system involvement is more specific with respect to the dorsal root ganglia. Thus, the early finding of dorsal root ganglion involvement correlates well with the ataxic neuropathy, as does the proportionately reduced fiber densities in sural nerve biopsies in ataxic and painful sensory neuropathies. Motor peripheral neuropathies also may occur due to vasculitis or antibody mediated demyelination (CIPD).

Therapy of neuropathies may include corticosteroids, IV-Ig, immune suppressant therapy including cyclophosphamide and perhaps biologic agents.

Central nervous involvement may involve both white and grey matter. Vasculitis as well as thrombotic and atherosclerotic manifestations must be 
considered. Newer MRI imaging techniques may help identify structural damage in the CNS and spinal cord. Recent studies have identified a much lower incidence of demyelinating disease (approximately $5 \%$ or less) than was reported in previous years.

Central sensitization (fibromyalgia) and chronic fatigue remain a challenge to diagnosis as assessment of therapy. Recent studies in mice demonstrate that changes in cytokines and adrenal-axis stress hormones strongly influence behavior without detectable associated change in brain structure $(14,184-186)$. This "stress" effect on memory and multi-tasking in mice also can be reproduced with effect of stress on healthy adults(187). Thus, neurological symptoms in SS patients present a diagnostic and therapeutic challenge that bridges immune activity, thrombotic complications, and manifestations from local cytokine release or hypothalamic axis alterations that may play a role in fibromyalgia.

\section{Speculations on the relationship of neurologic and lacrimal/salivary aspects of Sjogren's syndrome}

In summary, we have a variety of neurologic manifestations resulting from microvasculitis due to T-cell and dendritic cells, antibody mediated mechanisms, hormonally related factors and the complement/coagulation pathways. In each of these acquired and innate immune systems, the release of cytokines and chemokines is activated. Thus, SS appears to represent an intersection of immune, hormonal, endocrine and exocrine function. Each of these "immune" 
systems will influence neural function and the action of neurotransmitter on the end organ.

Thus, we can look at the body of neurologic data in the mirror of our knowledge about salivary/lacrimal gland biopsies and function presented in other chapters. The salivary and lacrimal glands develop embryologically from the same brachial cleft as the brain and neural system. Thus in a sense, the glands are "hard wired" to the neural system from the time of development. The degree of xerostomia in patients with Sjögren's syndrome does not correlate with degree of glandular destruction on biopsy (188). Thus, the release of cytokines and other factors paralyzes the function of the residual glands. It is likely that the release of similar factors influence the function of peripheral nerves and those in the central nervous system. Thus, studies of nerve-gland function and biopsy presented in other chapters will need to be applied to our understanding of neurologic manifestations of SS. In the past, we were limited to sural or other nerve biopsies for evaluation of neuropathic processes. The methods of skin biopsy stained for neural markers may be modified to include immune markers so that correlation with changes on minor salivary gland biopsies can be made. Thus, we now have two sites that can be safely biopsied (glandular and extraglandular) to obtain a better understanding of pathogenesis and to direct therapy. 


\section{REFERENCES}

1. Tajima Y, Mito Y, Owada Y, Tsukishima E, Moriwaka F, Tashiro K. Neurological manifestations of primary Sjögren's syndrome in Japanese patients. Intern Med. 1997 Oct;36(10):690-3.

2: Govoni M, Bajocchi G, Rizzo N, Tola MR, Caniatti L, Tugnoli V, Colamussi P, Trotta F. Neurological involvement in primary Sjögren's syndrome: clinical and instrumental evaluation in a cohort of Italian patients. Clin Rheumatol. 1999;18(4):299-303.

3: Delalande S, de Seze J, Fauchais AL, Hachulla E, Stojkovic T, Ferriby D, Dubucquoi S, Pruvo JP, Vermersch P, Hatron PY. Neurological manifestations in primary Sjögren syndrome: a study of 82 patients. Medicine (Baltimore). 2004 Sep;83(5):280-91.

4: Gemignani F, Marbini A, Pavesi G, Di Vittorio S, Manganelli P, Cenacchi G, Mancia D. Peripheral neuropathy associated with primary Sjögren's syndrome. J Neurol Neurosurg Psychiatry. 1994 Aug;57(8):983-6.

5: Servioli L, Pérez C, Consani S, Suárez A, Sehabiaga G, Collazo C, Catalá G. Prevalence and characteristics of immunomediated neuropathies in a group of patients with autoimmune diseases.

J Clin Neuromuscul Dis. 2007 Dec;9(2):285-90.

6: Mellgren SI, Göransson LG, Omdal R. Primary Sjögren's syndrome associated neuropathy. Can J Neurol Sci. 2007 Aug;34(3):280-7. Review.

7: Alexander EL. Neurological disease in Sjögren's syndrome. In: Aminoff MJ and Goetz CG eds. Handbook of Clinical Neurology 27 (71): Systemic Diseases, Part III Elsevier Science 1998: 59-98.

8: Grant IA, Hunder GG, Homburger HA, Dyck PJ. Peripheral neuropathy associated with sicca complex. Neurology. 1997 Apr;48(4):855-62.

9: Mori K, lijima M, Koike H, Hattori N, Tanaka F, W atanabe $H$, Katsuno M, Fujita A, Aiba I, Ogata A, Saito T, Asakura K, Yoshida M, Hirayama M, Sobue G. The wide spectrum of clinical manifestations in Sjögren's syndrome-associated neuropathy. Brain. 2005 Nov;128(Pt 11):2518-34. Epub 2005 Jul 27.

10: Kaplan JG, Rosenberg R, Reinitz E, Buchbinder S, Schaumburg HH. Invited review: peripheral neuropathy in Sjögren's's syndrome. Muscle Nerve. 1990 Jul;13(7):570-9. Review.

11: Graus F, Pou A, Kanterewicz E, Anderson NE. Sensory neuronopathy and Sjögren's syndrome: clinical and immunologic study of two patients. Neurology. 1988 Oct;38(10):1637 9.

12: Kaplan JG, Schaumburg HH. Predominantly unilateral sensory neuronopathy in Sjögren's syndrome. Neurology. 1991 Jun;41(6):948-9. No abstract available. 13: Mori K, Koike H, Misu K, Hattori N, Ichimura M, Sobue G. Spinal cord magnetic resonance imaging demonstrates sensory neuronal involvement and clinical severity in neuronopathy associated with Sjögren's syndrome.: J Neurol Neurosurg Psychiatry. 2001 Oct;71(4):488-92.

14: Chai J, Herrmann DN, Stanton M, Barbano RL, Logigian EL. Painful small- 
fiber neuropathy in Sjögren's syndrome. Neurology. 2005 Sep 27;65(6):925-7. 15: Mellgren SI, Conn DL, Stevens JC, Dyck PJ. Peripheral neuropathy in primary Sjögren's syndrome. Neurology. 1989 Mar;39(3):390-4.

16: Lacomis D. Small-fiber neuropathy. Muscle Nerve. 2002 Aug;26(2):173-88.

Review.

17: Periquet MI, Novak V, Collins MP, Nagaraja HN, Erdem S, Nash SM, Freimer ML, Sahenk Z, Kissel JT, Mendell JR. Painful sensory neuropathy: prospective evaluation using skin biopsy. Neurology. 1999 Nov 10;53(8):1641-7.

18: Koike H, Sobue G. Alcoholic neuropathy. Curr Opin Neurol. 2006 Oct;19(5):481-6. Review.

19: Laaksonen SM, Röyttä M, Jääskeläinen SK, Kantola I, Penttinen M, Falck B. Neuropathic symptoms and findings in women with Fabry disease. Clin Neurophysiol. 2008 Jun;119(6):1365-72. Epub 2008 Apr 1.

20: Devigili G, Tugnoli V, Penza P, Camozzi F, Lombardi R, Melli G, Broglio L, Granieri E, Lauria G. The diagnostic criteria for small fibre neuropathy: from symptoms to neuropathology. Brain. 2008 Jul;131(Pt 7):1912-25. Epub 2008 Jun 4.

21: Sobue G. Pathophysiology of sensory ataxic neuropathy. Rinsho Shinkeigaku. 1996 Dec;36(12):1356-7.

22: Smith BE, Windebank AJ and Dyck PJ. Nonmalignant Inflammatory Sensory Polyganglionopathy. In: Dyck PJ, Thomas PK. eds. Peripheral Neuropathy 4th ed. Elsevier Saunders philadelphia PA 2005: 2309-2320.

23: Malinow K, Yannakakis GD, Glusman SM, Edlow DW, Griffin J, Pestronk A, Powell DL, Ramsey-Goldman R, Eidelman BH, Medsger TA Jr, et al. Subacute sensory neuronopathy secondary to dorsal root ganglionitis in primary Sjögren's syndrome. Ann Neurol. 1986 Oct;20(4):535-7.

24: Griffin JW, Cornblath DR, Alexander E, Campbell J, Low PA, Bird S, Feldman EL. Ataxic sensory neuropathy and dorsal root ganglionitis associated with Sjögren's syndrome. Ann Neurol. 1990 Mar;27(3):304-15.

25: Bromberg M.B. Acute and Chronic Dysimmune Polyneuropathies. In: Brown W.F., Bolton C.F. and Amnoff M.J.eds. Neuromuscular Function and Disease. W.B. Saunders Company Philadelphia, PA 2002:1041-1060.

26: Gøransson LG, Herigstad A, Tjensvoll AB, Harboe E, Mellgren SI, Omdal R. Peripheral neuropathy in primary Sjögren's syndrome: a population-based study. Arch Neurol. 2006 Nov;63(11):1612-5.

27: Terrier B, Lacroix C, Guillevin L, Hatron PY, Dhote R, Maillot F, Diot E, Sarrot-Reynauld F, Sordet C, Dubourg O, Meyer L, Mariette X, Gottenberg JE; Club Rhumatismes et Inflammation. Diagnostic and prognostic relevance of neuromuscular biopsy in primary Sjögren's syndrome-related neuropathy. Arthritis Rheum. 2007 Dec 15;57(8):1520-9.

28: Collins MP and Kissel JT. Neuropathies with systemic vasculitis. In: Dyck PJ, Thomas PK. eds. Peripheral Neuropathy. Elsevier Saunders Philadelphia PA 2005: 2335-2404.

29: Vitali C, Tavoni A, Neri R, Castrogiovanni P, Pasero G, Bombardieri S. Fibromyalgia features in patients with primary Sjögren's syndrome. Evidence of a relationship with psychological depression. Scand J Rheumatol. 1989;18(1):21-7. 
30: Tishler M, Barak Y, Paran D, Yaron M. Sleep disturbances, Fibromyalgia and primary Sjögren's syndrome. Clin Exp Rheumatol. 1997 Jan-Feb;15(1):71-4.

31: Ringel SP, Forstot JZ, Tan EM, W ehling C, Griggs RC, Butcher D. Sj0gren's syndrome and polymyositis or dermatomyositis. Arch Neurol. 1982 Mar;39(3):157-63.

32: Cody D, Davidson J. Juvenile dermatomyositis and Sjögren's's syndrome occurring concurrently in an adolescent male. Rheumatology (Oxford). 2002 Jun;41(6):698-700. PubMed PMID: 12048300.

33: Kanellopoulos P, Baltoyiannis C, Tzioufas AG. Primary Sjögren's's syndrome associated with inclusion body myositis. Rheumatology (Oxford). 2002 Apr;41(4):440-4. PubMed PMID: 11961175.

34: Lindvall B, Bengtsson A, Ernerudh J, Eriksson P Subclinical myositis is common in primary Sjögren's syndrome and is not related to muscle pain. $\mathrm{J}$ Rheumatol. 2002 Apr;29(4):717-25.

35: Engel $A G$ and Hohlfeld R. The Polymyositis and Dermatomysitis Syndromes. In: Engel AG and Franzini-Armstrong C., eds. Myology 3 ed. rd New York, NY McGraw-Hill 2004: 1321-1366.

36: Sakakibara R, Hirano S, Asahina M, Sawai S, Nemoto Y, Hiraga A, Uchiyama T, Hattori T. Primary Sjögren's's syndrome presenting with generalized autonomic failure. Eur J Neurol. 2004 Sep;11(9):635-8.

37. Kumazawa K, Sobue G, Yamamoto K, Mitsuma T. Segmental anhidrosis in the spinal dermatomes in Sjögren's syndrome-associated neuropathy. Neurology. 1993 Sep;43(9):1820-3.

38: Cai FZ, Lester S, Lu T, Keen H, Boundy K, Proudman SM, Tonkin A, Rischmueller M. Mild autonomic dysfunction in primary Sjögren's syndrome: a controlled study. Arthritis Res Ther. 2008;10(2):R31. Epub 2008 Mar 7.

39: Mandl T, Granberg V, Apelqvist J, W ollmer P, Manthorpe R, Jacobsson LT. Autonomic nervous symptoms in primary Sjögren's's syndrome. Rheumatology (Oxford). 2008 Jun;47(6):914-9. Epub 2008 Apr 14.

40: Wright RA, Grant IA, Low PA. Autonomic neuropathy associated with sicca complex. J Auton Nerv Syst. 1999 Jan 15;75(1):70-6.

41: Hocevar A, Tomsic M, Praprotnik S, Hojnik M, Kveder T, Rozman B.

Parasympathetic nervous system dysfunction in primary Sjögren's syndrome. Ann Rheum Dis. 2003 Aug;62(8):702-4. Review.

42: Wang F, Jackson MW, Maughan V, Cavill D, Smith AJ, Waterman SA, Gordon TP. Passive transfer of Sjögren's's syndrome IgG produces the pathophysiology of overactive bladder. Arthritis Rheum. 2004 Nov;50(11):363745.

43: Waterman SA, Gordon TP, Rischmueller M. Inhibitory effects of muscarinic receptor autoantibodies on parasympathetic neurotransmission in Sjögren's syndrome. Arthritis Rheum. $2000 \mathrm{Jul} ; 43(7): 1647-54$.

44: Mandl T, Bornmyr SV, Castenfors J, Jacobsson LT, Manthorpe R, W ollmer P. Sympathetic dysfunction in patients with primary Sjögren's syndrome. J Rheumatol. 2001 Feb;28(2):296-301.

45: Low PA, Vernino S, Suarez G. Autonomic dysfunction in peripheral nerve disease. Muscle Nerve. 2003 Jun;27(6):646-61. Review. 
46: Kovács L, Paprika D, Tákacs R, Kardos A, Várkonyi TT, Lengyel C, Kovács A, Rudas L, Pokorny G. Cardiovascular autonomic dysfunction in primary Sjögren's syndrome. Rheumatology (Oxford). 2004 Jan;43(1):95-9. Epub 2003 Aug 29.

47: Mori K, lijima M, Sugiura M, Koike H, Hattori N, Ito H, Hirayama M, Sobue G. Sjögren's syndrome associated painful sensory neuropathy without sensory ataxia. J Neurol Neurosurg Psychiatry. 2003 Sep;74(9):1320-2. No abstract available. Erratum in: J Neurol Neurosurg Psychiatry. 2003 Oct;74(10):1447. 48: Vianello M, Vitaliani R, Pezzani R, Nicolao P, Betterle C, Keir G, Thompson EJ, Tavolato B, Scaravilli F, Giometto B. The spectrum of antineuronal autoantibodies in a series of neurological patients. J Neurol Sci. 2004 May 15;220(1-2):29-36.

49: Sobue G, Yasuda T, Kumazawa K, Yamamoto K, Mitsuma T. MRI demonstrates dorsal column involvement of the spinal cord in Sjögren's syndrome-associated neuropathy. Neurology. 1995 Mar;45(3 Pt 1):592-3. 50: Gøransson LG, Brun JG, Harboe E, Mellgren SI, Omdal R. Intraepidermal nerve fiber densities in chronic inflammatory autoimmune diseases. Arch Neurol. 2006 Oct;63(10):1410-3.

51: Engel $A G$ and Hohlfeld R. The Polymyositis and Dermatomysitis Syndromes. In: Engel AG and Franzini-Armstrong C. Eds. Myology 3 rd ed. McGraw-Hill New York, NY 2004: 1343-1344

52: Urban PP, Keilmann A, Teichmann EM, Hopf HC. Sensory neuropathy of the trigeminal, glossopharyngeal, and vagal nerves in Sjögren's syndrome. J Neurol Sci. 2001 May 1;186(1-2):59-63.

53: Alexander EL. Central nervous system (CNS) manifestations of primary Sjögren's syndrome: an overview. Scand J Rheumatol Suppl. 1986;61:161-5. 54: García-Carrasco M, Ramos-Casals M, Rosas J, Pallarés L, Calvo-Alen J, Cervera R, Font J, Ingelmo M. Primary Sjögren syndrome: clinical and immunologic disease patterns in a cohort of 400 patients. Medicine (Baltimore). 2002 Jul;81(4):270-80. Review.

55: Anaya JM, Villa LA, Restrepo L, Molina JF, Mantilla RD, Vargas S. Central nervous system compromise in primary Sjögren's syndrome. J Clin Rheumatol. 2002 Aug;8(4):189-96.

56: Mauch E, Völk C, Kratzsch G, Krapf H, Kornhuber HH, Laufen H, Hummel KJ Neurological and neuropsychiatric dysfunction in primary Sjögren's syndrome. Acta Neurol Scand. 1994 Jan;89(1):31-5.

57: McDonald I. Diagnostic methods and investigation in multiple sclerosis. In: Ebers G, Lassmann H, McDonald I, Matthhews B and Wekerle H, eds McAlpine's Multiple Sclerosis. London: Churchill Livingstone; 1998: 251.

58: Zeis T, Graumann U, Reynolds R, Schaeren-Wiemers N. Normal-appearing white matter in multiple sclerosis is in a subtle balance between inflammation and neuroprotection. Brain. 2008 Jan;131(Pt 1):288-303. Epub 2007 Dec 4.

59: Alexander EL, Malinow K, Lejewski JE, Jerdan MS, Provost TT, Alexander GE. Primary Sjögren's syndrome with central nervous system disease mimicking multiple sclerosis. Ann Intern Med. 1986 Mar;104(3):323-30.

60: Noseworthy JH, Bass BH, Vandervoort MK, Ebers GC, Rice GP, 
Weinshenker BG, McLay CJ, Bell DA. The prevalence of primary Sjögren's syndrome in a multiple sclerosis population. Ann Neurol. 1989 Jan;25(1):95-8. 61: Sandberg-Wollheim M, Axéll T, Hansen BU, Henricsson V, Ingesson E, Jacobsson L, Larsson A, Lieberkind K, Manthorpe R. Primary Sjögren's syndrome in patients with multiple sclerosis. Neurology. 1992 Apr;42(4):845-7. 62: Miró J, Peña-Sagredo JL, Berciano J, Insúa S, Leno C, Velarde R.

Prevalence of primary Sjögren's syndrome in patients with multiple sclerosis. Ann Neurol. 1990 May;27(5):582-4.

63: W ang YJ, Tsai KY, Fuh JL, Tsai CP, Wang SJ. High frequency of primary Sjögren's syndrome in Taiwanese patients presenting as relapsing-remitting multiple sclerosis. Eur Neurol. 2004;51(1):21-5. Epub 2003 Nov 18.

64: de Seze J, Devos D, Castelnovo G, Labauge P, Dubucquoi S, Stojkovic T, Ferriby $D$, Vermersch $P$. The prevalence of Sjögren syndrome in patients with primary progressive multiple sclerosis. Neurology. 2001 Oct 23;57(8):1359-63. 65: Pericot I, Brieva L, Tintoré M, Río J, Sastre-Garriga J, Nos C, Montalban X. Myelopathy in seronegative Sjögren syndrome and/or primary progressive multiple sclerosis. Mult Scler. 2003 Jun;9(3):256-9.

66: Tsai KY, Tsai CP, Liao N. Sjögren's syndrome with central nervous system involvement presenting as multiple sclerosis with failure response to betainterferon. Eur Neurol. 2001;45(1):59-60. No abstract available.

67: Alexander EL. Neurological disease in Sjögren's syndrome: mononuclear inflammatory vasculopathy affecting central/peripheral nervous system and muscle. A clinical review and update of immunopathogenesis. Rheum Dis Clin North Am. 1993 Nov;19(4):869-908. Review.

68: Moore PM, Lisak RP. Multiple sclerosis and Sjögren's syndrome: a problem in diagnosis or in definition of two disorders of unknown etiology? Ann Neurol. 1990 May;27(5):585-6. Review. No abstract available.

69: Chang CP, Shiau YC, Wang JJ, Ho ST, Kao A. Abnormal regional cerebral blood flow on 99mTc ECD brain SPECT in patients with primary Sjögren's syndrome and normal findings on brain magnetic resonance imaging. Ann Rheum Dis. 2002 Sep;61(9):774-8.

70: Belin C, Moroni C, Caillat-Vigneron N, Debray M, Baudin M, Dumas JL, Moretti JL, Delaporte P, Guillevin L. Central nervous system involvement in Sjögren's syndrome: evidence from neuropsychological testing and HMPAOSPECT. Ann Med Interne (Paris). 1999 Dec;150(8):598-604.

71: Kawashima N, Shindo R, Kohno M. Primary Sjögren's syndrome with subcortical dementia. Intern Med. 1993 Jul;32(7):561-4.

72: Caselli RJ, Scheithauer BW, Bowles CA, Trenerry MR, Meyer FB, Smigielski JS,

Rodriguez M. The treatable dementia of Sjögren's syndrome. Ann Neurol. 1991 Jul;30(1):98-101.

73: Orman B, Sterin-Borda L, De Couto Pita A, Reina S, Borda E. Anti-brain cholinergic auto antibodies from primary Sjögren syndrome sera modify simultaneously cerebral nitric oxide and prostaglandin biosynthesis. Int Immunopharmacol. 2007 Dec 5;7(12):1535-43. Epub 2007 Aug 16.

74: Liberatore GT, Jackson-Lewis V, Vukosavic S, Mandir AS, Vila M, McAuliffe 
WG, Dawson VL, Dawson TM, Przedborski S. Inducible nitric oxide synthase stimulates dopaminergic neurodegeneration in the MPTP model of Parkinson disease. Nat Med. 1999 Dec;5(12):1403-9.

75: Kim EJ, Lee JE, Kwon KJ, Lee SH, Moon CH, Baik EJ. Differential roles of cyclooxygenase isoforms after kainic acid-induced prostaglandin $\mathrm{E}(2)$ production and neurodegeneration in cortical and hippocampal cell cultures. Brain Res. 2001 Jul 20;908(1):1-9.

76: Visser LH, Koudstaal PJ, van de Merwe JP. Hemiparkinsonism in a patient with primary Sjögren's syndrome. A case report and a review of the literature. Clin Neurol Neurosurg. 1993 Jun;95(2):141-5.

77: Hassin-Baer S, Levy Y, Langevitz P, Nakar S, Ehrenfeld M. Anti-beta2glycoprotein I in Sjögren's's syndrome is associated with parkinsonism. Clin Rheumatol. 2007 May;26(5):743-7. Epub 2006 Oct 21.

78: Hashimoto S, Sawada T, Inoue T, Yamamoto K, Iwata M. Cholinergic-drug induced sicca syndrome in Parkinson's disease: a case report and a review of the literature. Clin Neurol Neurosurg. 1999 Dec;101(4):268-70. Review.

79: Venegas Fanchke P, Sinning M, Miranda M. Primary Sjögren's's syndrome presenting as a generalized chorea. Parkinsonism Relat Disord. 2005 May;11(3):193-4.

80: Nishimura H, Tachibana H, Makiura N, Okuda B, Sugita M. Corticosteroidresponsive parkinsonism associated with primary Sjögren's syndrome. Clin Neurol Neurosurg. 1994 Nov;96(4):327-31.

81: Créange A, Sedel F, Brugières P, Voisin MC, Degos JD. Primary Sjögren's syndrome presenting as progressive parkinsonian syndrome. Mov Disord. 1997 Jan;12(1):121-3. No abstract available.

82: W alker RH, Spiera H, Brin MF, Olanow CW. Parkinsonism associated with Sjögren's syndrome: three cases and a review of the literature. Mov Disord. 1999 Mar; 14(2):262-8. Review.

83: Papageorgiou SG, Kontaxis T, Bonakis A, Kalfakis N. Orofacial dystonia related to Sjögren's's syndrome. Clin Rheumatol. 2007 Oct;26(10):1779-81. Epub 2007 Jan 16.

84: Alexander EL, Alexander GE. Aseptic meningoencephalitis in primary Sjögren's syndrome. Neurology. 1983 May;33(5):593-8.

85: Hirohata M, Yasukawa Y, Ishida C, Komai K, Yamada M. Reversible cortical lesions in primary Sjögren's syndrome presenting with meningoencephalitis as an initial manifestation. J

Neurol Sci. 2005 May 15;232(1-2):111-3.

86: Rossi R, Valeria Saddi M. Subacute aseptic meningitis as neurological manifestation of primary Sjögren's syndrome. Clin Neurol Neurosurg. 2006 Oct;108(7):688-91. Epub 2005 Jul 28.

87: Ishida K, Uchihara T, Mizusawa H. Recurrent aseptic meningitis: a new CSF complication of Sjögren's's syndrome. J Neurol. 2007 Jun;254(6):806-7. Epub 2007 Apr 9. No abstract available.

88: Hoshina T, Yamaguchi Y, Ohga S, Kira R, Ishimura M, Takada H, Tanaka T, Hara T. Sjögren's's syndrome-associated meningoencephalomyelitis: cerebrospinal fluid cytokine levels and therapeutic utility of tacrolimus. J Neurol 
Sci. 2008 Apr 15;267(1-2):182-6. Epub 2007 Nov 9.

89: Caselli RJ, Scheithauer BW, O'Duffy JD, Peterson GC, Westmoreland BF, Davenport PA. Chronic inflammatory meningoencephalitis should not be mistaken for Alzheimer's disease. Mayo Clin Proc. 1993 Sep;68(9):846-53. 90: Gerraty RP, McKelvie PA, Byrne E. Aseptic meningoencephalitis in primary Sjögren's syndrome. Response to plasmapheresis and absence of CNS vasculitis at autopsy. Acta Neurol Scand. 1993 Oct;88(4):309-11.

91: Niemelä RK, Hakala M. Primary Sjögren's syndrome with severe central nervous system disease. Semin Arthritis Rheum. 1999 Aug;29(1):4-13. Review. 92: W ong S, Pollock AN, Burnham JM, Sherry DD, Dlugos DJ. Acute cerebellar ataxia due to Sjögren syndrome. Neurology. 2004 Jun 22;62(12):2332-3. 93: Urban $\mathrm{E}$, Jabbari $\mathrm{B}$, Robles $\mathrm{H}$. Concurrent cerebral venous sinus thrombosis and myeloradiculopathy in Sjögren's syndrome. Neurology. 1994 Mar;44(3 Pt 1):554-6.

94: Hayashi Y, Kimura A, Kato S, Koumura A, Sakurai T, Tanaka Y, Hozumi I, Sunden Y, Orba Y, Sawa H, Takahashi H, Inuzuka T. Progressive multifocal leukoencephalopathy and CD4+ T-lymphocytopenia in a patient with Sjögren syndrome. J Neurol Sci. 2008 May 15;268(1-2):195-8. Epub 2008 Jan 29. 95: Li JY, Lai PH, Lam HC, Lu LY, Cheng HH, Lee JK, Lo YK. Hypertrophic cranial pachymeningitis and lymphocytic hypophysitis in Sjögren's syndrome. Neurology. 1999 Jan 15;52(2):420-3.

96: Alexander EL, Ranzenbach MR, Kumar AJ, Kozachuk WE, Rosenbaum AE, Patronas N, Harley JB, Reichlin M. Anti-Ro(SS-A) autoantibodies in central nervous system disease associated with Sjögren's syndrome (CNS-SS): clinical, neuroimaging, and angiographic correlates. Neurology. 1994 May;44(5):899-908. 97: de Seze J, Dubucquoi S, Fauchais AL, Matthias T, Devos D, Castelnovo G, Stojkovic T, Ferriby D, Hachulla E, Labauge P, Lefranc D, Hatron PY, Vermersch $\mathrm{P}$, Witte T. Alpha-fodrin autoantibodies in the differential diagnosis of MS and Sjögren's syndrome. Neurology. 2003 Jul 22;61(2):268-9. No abstract available. 98: Bourahoui A, De Seze J, Guttierez R, Onraed B, Hennache B, Ferriby D, Stojkovic T, Vermersch P. CSF isoelectrofocusing in a large cohort of MS and other neurological diseases. Eur J Neurol. 2004 Aug;11(8):525-9.

99: Vrethem M, Ernerudh J, Lindström F, Skogh T. Immunoglobulins within the central nervous system in primary Sjögren's syndrome.J Neurol Sci. 1990 Dec;100(1-2):186-92. 100: Mégevand P, Chizzolini C, Chofflon M, RouxLombard P, Lalive PH, Picard F. Cerebrospinal fluid anti-SSA autoantibodies in primary Sjögren's's syndrome with central nervous system involvement. Eur Neurol. 2007;57(3):166-71. Epub 2007 Jan 10. Erratum in: Eur Neurol. 2007 Mar;57(3):190A.

101: Coates T, Slavotinek JP, Rischmueller M, Schultz D, Anderson C, Dellamelva M, Sage MR, Gordon TP. Cerebral white matter lesions in primary Sjögren's syndrome: a controlled study. J Rheumatol. 1999 Jun;26(6):1301-5. 102: Alexander EL, Beall SS, Gordon B, Selnes OA, Yannakakis GD, Patronas $\mathrm{N}$, Provost TT, McFarland HF. Magnetic resonance imaging of cerebral lesions in patients with the Sjögren syndrome. Ann Intern Med. 1988 Jun;108(6):815-23. 103: Morgen K, McFarland HF, Pillemer SR. Central nervous system disease in 
primary Sjögren's syndrome: the role of magnetic resonance imaging. Semin Arthritis Rheum. 2004

Dec;34(3):623-30. Review.

104: Kao CH, Lan JL, ChangLai SP, Chieng PU. Technetium-99m-HMPAO brain SPECT in

Sjögren's syndrome. J Nucl Med. 1998 May;39(5):773-7.

105: Kao CH, Ho YJ, Lan JL, ChangLai SP, Chieng PU. Regional cerebral blood flow and glucose

metabolism in Sjögren's syndrome. J Nucl Med. 1998 Aug;39(8):1354-6.

106: Lass P, Krajka-Lauer J, Homziuk M, Iwaszkiewicz-Bilikiewicz B, Koseda M, Hebanowski M, Lyczak P. Cerebral blood flow in Sjögren's syndrome using 99Tcm-HMPAO brain

SPET. Nucl Med Commun. 2000 Jan;21(1):31-5.

107: Caroyer JM, Manto MU, Steinfeld SD. Severe sensory neuronopathy responsive to infliximab

in primary Sjögren's syndrome. Neurology. 2002 Oct 8;59(7):1113-4. No abstract available.

108: Kizawa M, Mori K, lijima M, Koike H, Hattori N, Sobue G. Intravenous immunoglobulin treatment in painful sensory neuropathy without sensory ataxia associated with Sjögren's syndrome. J Neurol Neurosurg Psychiatry. 2006 Aug;77(8):967-9.

109: Takahashi Y, Takata T, Hoshino M, Sakurai M, Kanazawa I. Benefit of IVIG for long-standing ataxic sensory neuronopathy with Sjögren's syndrome. IV immunoglobulin. Neurology. 2003 Feb 11;60(3):503-5.

110: Rajabally YA, Seow H, Abbott RJ. Immunoglobulin-responsive dysautonomia in Sjögren's syndrome. J Neurol. 2007 May;254(5):674-5. Epub 2007 Apr 2. No abstract available.

111: Chen WH, Yeh JH, Chiu HC. Plasmapheresis in the treatment of ataxic sensory neuropathy associated with Sjögren's syndrome. Eur Neurol. 2001;45(4):270-4.

112: Gorson KC, Natarajan N, Ropper AH, W einstein R. Rituximab treatment in patients with IVIg-dependent immune polyneuropathy: a prospective pilot trial. Muscle Nerve. 2007 Jan;35(1):66-9.

113: Kastrup O, Maschke M, Diener HC. Pulse-cyclophosphamide in the treatment of ataxic sensory and cranial nerve neuropathy associated with Sjögren's's syndrome. Clin Neurol Neurosurg. 2005 Aug;107(5):440-1. Epub 2004 Nov 10.

114: Asahina M, Kuwabara S, Asahina M, Nakajima M, Hattori T. D-penicillamine treatment for chronic sensory ataxic neuropathy associated with Sjögren's syndrome. Neurology. 1998Nov;51(5):1451-3.

115: W yszynski AA, W yszynski B. Treatment of depression with fluoxetine in corticosteroid-dependent central nervous system Sjögren's syndrome.

Psychosomatics. 1993 Mar-Apr;34(2):173-7.

116: Grant IA and Dyck PJ (letter) High-dose IV immunoglobulin for peripheral neuropathy associated with Sjögren's syndrome. Neurology. 1998

Aug;51(2):650-1. 
117: Ozgocmen S, Gur A. Treatment of central nervous system involvement associated with primary Sjögren's syndrome. Curr Pharm Des. 2008;14(13):1270-3. Review.

118: Williams CS, Butler E, Román GC. Treatment of myelopathy in Sjögren syndrome with a combination of prednisone and cyclophosphamide. Arch Neurol. 2001 May;58(5):815-9. Review.

119:Rogers SJ, Williams CS, Román GC. Myelopathy in Sjögren's syndrome: role of nonsteroidal immunosuppressants. Drugs. 2004;64(2):123-32. Review. 120: de Seze J, Delalande S, Fauchais AL, Hachulla E, Stojkovic T, Ferriby D, Hatron PY, Vermersch P. Myelopathies secondary to Sjögren's syndrome: treatment with monthly intravenous cyclophosphamide associated with corticosteroids. J Rheumatol. 2006 Apr;33(4):709-11.

121: Wright RA, O'Duffy JD, Rodriguez M. Improvement of myelopathy in Sjögren's syndrome with chlorambucil and prednisone therapy. Neurology. 1999 Jan 15;52(2):386-8.

122: Yamout B, El-Hajj T, Barada W, Uthman I. Successful treatment of refractory neuroSjögren's with Rituximab. Lupus. 2007;16(7):521-3.

123: Canhão H, Fonseca JE, Rosa A. Intravenous gammaglobulin in the treatment of central nervous system vasculitis associated with Sjögren's syndrome. J Rheumatol. 2000 Apr;27(4):1102-3.

124: Konttinen YT, Kinnunen E, von Bonsdorff M, Lillqvist P, Immonen I, Bergroth V, Segerberg-Konttinen M, Friman C. Acute transverse myelopathy successfully treated with plasmapheresis and prednisone in a patient with primary Sjögren's syndrome.

additional refs

1. Delalande S, de Seze J, Fauchais AL, Hachulla E, Stojkovic T, Ferriby D, et al. Neurologic manifestations in primary Sjogren syndrome: a study of 82 patients. Medicine (Baltimore) 2004;83(5):280-91.

2. Goldenberg D. Fibromyalgia, chronic fatigue syndrome, and myofascial pain syndrome. Current opinion in rheumatology 1995;7(2):127.

3. Hanson P, Schumacker P, Clerin M. Evaluation of somatic and autonomic small fibers neuropathy in diabetes. American Journal of Physical Medicine \& Rehabilitation 1992;71(1):44.

4. Rodriquez A, Kanis L, Lane D. Somatosensory evoked potentials from dermatomal stimulation as an indicator of $L 5$ and $S 1$ radiculopathy. Archives of physical medicine and rehabilitation 1987;68(6):366.

5. Elert J, Rantap\%o\%-Dahlqvist S, Henriksson-Larsen K, Lorentzon R, Gerdle B. Muscle performance, electromyography and fibre type composition in fibromyalgia and work-related myalgia. Scandinavian journal of rheumatology 1992;21(1):28-34.

6. Bergdahl M, Bergdahl J, Johansson I. Depressive symptoms in individuals with idiopathic subjective dry mouth. J Oral Pathol Med 1997;26(10):448-50. 
7. Bronge L, Wahlund L, Brauner A, Basun $\mathrm{H}$, Garlind $A$. White matter lesions and soluble interleukin-1 receptor type II in CSF from demented and nondemented subjects. Neurochemistry international 2002;41(4):217-222.

8. Coates T, Slavotinek J, Rischmueller M, Schultz D, Anderson C, Dellamelva $\mathrm{M}$, et al. Cerebral white matter lesions in primary Sj'gren's syndrome: a controlled study. The Journal of rheumatology 1999;26(6):1301.

9. $\quad$ Pierot L, Sauve C, Leger J, Martin N, Koeger A, Wechsler B, et al. Asymptomatic cerebral involvement in Sj^gren's syndrome: MRI findings of 15 cases. Neuroradiology 1993;35(5):378-380.

10. Ramos-Casals M, Tzioufas A, Font J. Primary Sjogren's syndrome: new clinical and therapeutic concepts. British Medical Journal 2005;64(3):347.

11. Birnbaum J, Kirr D. Frequency of Neurologic Disease in Sjogren Syndrome patients versus controls. Arth Rheum 2009;60:506.

12. Birnbaum J, Petri M, Thompson R, Izbudak I, Kerr D. Distinct subtypes of myelitis in systemic lupus erythematosus. Arthritis Care \& Research 2009;60(11):3378-3387.

13. Harboe E, Beyer M, Greve O, G ${ }^{-}$ransson L, Tjensvoll A, Kval ${ }^{-}$J, et al. Cerebral white matter hyperintensities are not increased in patients with primary Sj'gren's syndrome. European Journal of Neurology 2009;16(5):576-581.

14. Harboe E, Tjensvoll A, Maroni S, Goransson L, Greve O, Beyer M, et al. Neuropsychiatric syndromes in patients with systemic lupus erythematosus and primary Sjogren syndrome: a comparative population-based study. British Medical Journal 2009;68(10):1541.

15. McDonald W, Compston A, Edan G, Goodkin D, Hartung H, Lublin F, et al. Recommended diagnostic criteria for multiple sclerosis: guidelines from the International Panel on the diagnosis of multiple sclerosis. Annals of neurology 2001;50(1):121-127.

16. Filippi M, Bozzali M, Rovaris M, Gonen O, Kesavadas C, Ghezzi A, et al. Evidence for widespread axonal damage at the earliest clinical stage of multiple sclerosis. Brain 2003;126(2):433.

17. Vaudo G, Bocci E, Shoenfeld Y, Schillaci G, Wu R, Del Papa N, et al. Precocious intima-media thickening in patients with primary $\mathrm{Sj}^{\wedge}$ gren's syndrome. Arthritis Care \& Research;52(12):3890-3897.

18. Shoenfeld Y, Gerli R, Doria A, Matsuura E, Cerinic M, Ronda N, et al. Accelerated atherosclerosis in autoimmune rheumatic diseases. Circulation 2005; 112(21):3337.

19. Fox RI. Sjogren's syndrome. Lancet 2005;366(9482):321-31.

20. Sanna G, Bertolaccini M, Cuadrado M, Laing H, Khamashta M, Mathieu A, et al. Neuropsychiatric manifestations in systemic lupus erythematosus: prevalence and association with antiphospholipid antibodies. J Rheumatol 2003;30(5):985-992.

21. Gemignani F, Marbini A, Pavesi G, Di Vittorio S, Manganelli P, Cenacchi $\mathrm{G}$, et al. Peripheral neuropathy associated with primary Sjogren's syndrome. J Neurol Neurosurg Psychiatry 1994;57(8):983-6. 
22. Mori K, lijima M, Koike H, Hattori N, Tanaka F, Watanabe H, et al. The wide spectrum of clinical manifestations in Sjogren's syndrome-associated neuropathy. Brain 2005;128(11):2518-2534.

23. Sghirlanzoni A, Pareyson D, Lauria G. Sensory neuron diseases. Lancet Neurology 2005;4(6):349-361.

24. Lafitte C, Amoura Z, Cacoub P, Pradat-Diehl P, Picq C, Salachas F, et al. Neurological complications of primary Sj ${ }^{\wedge}$ gren's syndrome. Journal of neurology 2001;248(7):577-584.

25. Alexander EL, Provost TT, Stevens MB, Alexander GE. Neurologic complications of primary Sjogren's syndrome. Medicine 1982;61(4):247.

26. Govoni M, Bajocchi G, Rizzo N, Tola MR, Caniatti L, Tugnoli V, et al. Neurological Involvement in Primary Sjo $\AA$ gren's Syndrome: Clinical and Instrumental Evaluation in a Cohort of Italian Patients. Clinical rheumatology 1999;18(4):299-303.

27. Chai J, Herrmann DN, Stanton M, Barbano RL, Logigian EL. Painful smallfiber neuropathy in Sjogren syndrome. Neurology 2005;65(6):925-927.

28. Moore PM, Lisak RP. Systemic lupus erythematosus:

immunopathogenesis of neurologic dysfunction. In; 1995: Springer; 1995. p. 4360.

29. Moore PM. Central nervous system vasculitis. Current opinion in neurology 1998;11(3):241.

30. McCombe PA. Neurological complications of connective tissue diseases and vasculitis. Autoimmune Neurological Disease 1995:345.

31. Goransson L, Brun J, Harboe E, Mellgren S, Omdal R. Intraepidermal nerve fiber densities in chronic inflammatory autoimmune diseases. Archives of Neurology 2006;63(10):1410.

32. Goransson L, Herigstad A, Tjensvoll A, Harboe E, Mellgren S, Omdal R. Peripheral neuropathy in primary sjogren syndrome: a population-based study. Archives of Neurology 2006;63(11):1612.

33. Grant I, Hunder G, Homburger H, Dyck P. Peripheral neuropathy associated with sicca complex. Neurology 1997;48(4):855.

34. Mori K, lijima M, Sugiura M, Koike H, Hattori N, Ito H, et al. Sjogren's syndrome associated painful sensory neuropathy without sensory ataxia. British Medical Journal 2003;74(9):1320.

35. Griffin J, Cornblath D, Alexander E, Campbell J, Low S. Ataxic Sensory Neuropathy and Dorsal Root Ganghonitis Associated with $S$ jogrenís Syndrome. 36. Malinow K, Yannakakis G, Glusman S, Edlow D, Griffin J, Pestronk A, et al. Subacute sensory neuronopathy secondary to dorsal root ganglionitis in primary Sj"gren's syndrome. Annals of neurology 1986;20(4):535-537.

37. Mellgren S, Conn D, Stevens J, Dyck P. Peripheral neuropathy in primary Sjogren's syndrome. Neurology 1989;39(3):390.

38. Mellgren S, G^ransson L, Omdal R. Primary Sj^gren's syndrome associated neuropathy. The Canadian Journal of Neurological Sciences 2007;34(3):280-287. 
39. Terrier B, Lacroix C, Guillevin L, Hatron P, Dhote R, Maillot F, et al. Diagnostic and prognostic relevance of neuromuscular biopsy in primary Sj’gren's syndrome-related neuropathy. Arthritis \& Rheumatism 2007;57(8). 40. Engel A, Hohlfeld R, Banker B. The polymyositis and dermatomyositis syndromes. myology 1994;2:1335-1383.

41. Lindvall B, Bengtsson A, Ernerudh J, Eriksson P. Subclinical myositis is common in primary Sjogren's syndrome and is not related to muscle pain. $\mathrm{J}$ Rheumatol 2002;29(4):717-25.

42. Chahin N, Engel AG. Correlation of muscle biopsy, clinical course, and outcome in PM and sporadic IBM. Neurology 2008;70(6):418-424.

43. Kissel JT, Mendell JR. Vasculitic neuropathy. Diagnosis and management of peripheral nerve disorders 2001:202.

44. Stevens MJ, Feldman EL, Thomas TP, Greene DA. The pathogenesis of diabetic neuropathy. Clinical Management of Diabetic Neuropathy 1998:13.

45. Hu S, Wang J, Meijer J, leong S, Xie Y, Yu T, et al. Salivary proteomic and genomic biomarkers for primary Sjogren's syndrome. Arthritis Rheum 2007;56(11):3588-600.

46. Taylor PV, Taylor KF, Norman A, Griffiths S, Scott JS. Prevalence of maternal Ro (SS-A) and La (SS-B) autoantibodies in relation to congenital heart block. Rheumatology 1988;27(2):128.

47. Buyon JP, Ben-Chetrit E, Karp S, Roubey RA, Pompeo L, Reeves WH, et al. Acquired congenital heart block. Pattern of maternal antibody response to biochemically defined antigens of the SSA/Ro-SSB/La system in neonatal lupus. Journal of Clinical Investigation 1989;84(2):627.

48. Waltuck J, Buyon JP. Autoantibody-associated congenital heart block: outcome in mothers and children. Annals of internal medicine 1994;120(7):544. 49. Logothetis J, Kennedy WR, Ellington A, Williams RC. Cryoglobulinemic Neuropathy: Incidence and Clinical Characteristics. Arch Neurol 1968;19(4):389397.

50. Hughes RAC. Inflammatory and immune mediated sensory neuropathies. Sensory Neuropathies 1995:151.

51. Griffin JW, Cornblath DR. Ataxic neuropathies. Sensory Neuropathies 1995:105.

52. Donfrid M, Apostolski S, Suvajdzic N, Jankovic G, Cemerikic-Martinovic V, Atkinson HDE, et al. Monocytoid B cell lymphoma associated with antibodies to myelin-associated glycoprotein and sulphated glucuronyl paragloboside. Acta Haematologica 2000;106(3):130-132.

53. Voltz R. Paraneoplastic neurological syndromes: an update on diagnosis, pathogenesis, and therapy. The Lancet Neurology 2002;1(5):294-305.

54. Bacman S, Sterin-Borda L, Camusso JJ, Arana R, Hubscher O, Borda E. Circulating antibodies against rat parotid gland M3 muscarinic receptors in primary Sjogren's syndrome. Clinical and Experimental Immunology 1996;104(3):454-459.

55. Watanabe T, Tsuchida T, Kanda N, Mori K, Hayashi Y, Tamaki K. Anti\{alpha\}-fodrin antibodies in Sjogren syndrome and lupus erythematosus.

Archives of Dermatology 1999;135(5):535. 
56. Kastrup O, Maschke M, Diener H. Pulseócyclophosphamide in the treatment of ataxic sensory and cranial nerve neuropathy associated with Sjogren's syndrome. Clinical neurology and neurosurgery 2005;107(5):440-441. 57. Mori K, lijima M, Koike H, Hattori N, Tanaka F, Watanabe H, et al. The wide spectrum of clinical manifestations in Sjogren's syndrome-associated neuropathy. Brain 2005;128(11):2518.

58. Delalande S, De Seze J, Fauchais A, Hachulla E, Stojkovic T, Ferriby D, et al. Neurologic manifestations in primary Sj'gren syndrome. Medicine 2004;83(5):280-291.

59. ANDONOPOULOS AP, LAGOS G, DROSOS AA, MOUTSOPOULOS HM. THE SPECTRUM OF NEUROLOGICAL INVOLVEMENT IN SJOGREN'S SYNDROME. Rheumatology 1990;29(1):21-24.

60. Font J, Valls J, Cervera R, Pou A, Ingelmo M, Graus F. Pure sensory neuropathy in patients with primary Sjogren's syndrome: clinical, immunological, and electromyographic findings. British Medical Journal 1990;49(10):775.

61. Mori A, Shimazaki J, Shimmura S, Fujishima H, Oguchi Y, Tsubota K. Disposable eyelid-warming device for the treatment of meibomian gland dysfunction. Jpn J Ophthalmol 2003;47(6):578-86.

62. Mori K, Koike H, Misu K, Hattori N, Ichimura M, Sobue G. Spinal cord magnetic resonance imaging demonstrates sensory neuronal involvement and clinical severity in neuronopathy associated with Sjogren's syndrome. British Medical Journal 2001;71(4):488.

63. Kachi T, Sobue G, Yamamoto M, Igata A. Sensory conduction study in chronic sensory ataxic neuropathy. British Medical Journal 1994;57(8):941.

64. Sakakibara R, Hirano S, Asahina M, Sawai S, Nemoto Y, Hiraga A, et al. Primary Sjogren's syndrome presenting with generalized autonomic failure. European Journal of Neurology 2004;11(9):635-638.

65. Kovacs L, Paprika D, Takacs R, Kardos A, Varkonyi TT, Lengyel C, et al. Cardiovascular autonomic dysfunction in primary Sjogren's syndrome. Rheumatology 2004;43(1):95-99.

66. Straub R, Baerwald C, Wahle M, J\%onig W. Autonomic dysfunction in rheumatic diseases. Rheumatic Disease Clinics of NOrth America 2005;31(1):6175.

67. Kumazawa K, Sobue G, Yamamoto K, Mitsuma T. Segmental anhidrosis in the spinal dermatomes in Sj'gren's syndrome-associated neuropathy. Neurology 1993;43(9):1820.

68. Mandl T, Bornmyr S, Castenfors J, Jacobsson L, Manthorpe R, Wollmer P. Sympathetic dysfunction in patients with primary Sjarenís syndrome. J Rheumatol 2001;28(2):296-301.

69. Mandl T, Granberg V, Apelqvist J, Wollmer P, Manthorpe R, Jacobsson L. Autonomic nervous symptoms in primary Sjogren's; syndrome. Rheumatology 2008.

70. Wright R, Grant I, Low P. Autonomic neuropathy associated with sicca complex. Journal of the autonomic nervous system 1999;75(1):70-76.

71. Sobue G. Pathophysiology of sensory ataxic neuropathy. Rinsh shinkeigaku= Clinical neurology 1996;36(12):1356. 
72. Sobue G, Yasuda T, Kumazawa K, Yamamoto K, Mitsuma T. MRI demonstrates dorsal column involvement of the spinal cord in Sj gren's syndrome-associated neuropathy. Neurology 1995;45(3):592-593.

73. Lin C, Chiu M. Teaching Neurolmage: Cervical cord atrophy with dorsal root ganglionopathy in Sjogren syndrome. Neurology 2008;70(7):e27.

74. TAJIMA Y, MITO Y, OWADA Y, TSUKISHIMA E, MORIWAKA F, TASHIRO K. Neurological Manifestations of Primary Sj'gren"s Syndrome in Japanese Patients. Internal Medicine 1997;36(10):690-693.

75. Govoni M, Bajocchi G, Rizzo N, Tola M, Caniatti L, Tugnoli V, et al. Neurological Involvement in Primary Sjo $®$ gren's Syndrome: Clinical and Instrumental Evaluation in a Cohort of Italian Patients. Clinical rheumatology 1999;18(4):299-303.

76. Gemignani F, Marbini A, Pavesi G, Di Vittorio S, Manganelli P, Cenacchi $G$, et al. Peripheral neuropathy associated with primary Sjogren's syndrome. British Medical Journal 1994;57(8):983.

77. Servioli L, PĖrez C, Consani S, Su.rez A, Sehabiaga G, Collazo C, et al. Prevalence and characteristics of immunomediated neuropathies in a group of patients with autoimmune diseases. Journal of Clinical Neuromuscular Disease 2007;9(2):285.

78. Vetrugno R, Liguori R, Cortelli P, Montagna P. Sympathetic skin response. Clinical Autonomic Research 2003;13(4):256-270.

79. Kaplan J, Rosenberg R, Reinitz E, Buchbinder S, Schaumburg H. Invited review: Peripheral neuropathy in Sjogren' syndrome. Muscle \& Nerve 1990;13(7):570-579.

80. Graus F, Pou A, Kanterewicz E, Anderson N. Sensory neuronopathy and

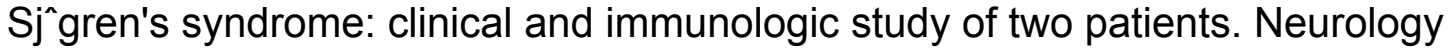
1988;38(10):1637.

81. Chai J, Herrmann D, Stanton M, Barbano R, Logigian E. Painful smallfiber neuropathy in Sjogren syndrome. Neurology 2005;65(6):925.

82. Kaplan J, Schaumburg H. PREDOMINANTLY UNILATERAL SENSORY NEURONOPATHY IN SJOGREN'S SYNDROME. Neurology 1991;41(6):948949.

83. Lacomis D. Small-fiber neuropathy. Muscle \& Nerve 2002;26(2):173-188.

84. Periquet M, Novak V, Collins M, Nagaraja H, Erdem S, Nash S, et al.

Painful sensory neuropathy: prospective evaluation using skin biopsy. Neurology 1999;53(8):1641.

85. Koike H, Sobue G. Alcoholic neuropathy. Current opinion in neurology 2006;19(5):481.

86. Laaksonen S, R^ytt\%o M, J\%o\%skel\%oinen S, Kantola I, Penttinen M, Falck B. Neuropathic symptoms and findings in women with Fabry disease. Clinical Neurophysiology 2008;119(6):1365-1372.

87. Devigili G, Tugnoli V, Penza P, Camozzi F, Lombardi R, Melli G, et al. The diagnostic criteria for small fibre neuropathy: from symptoms to neuropathology. Brain 2008;131(7):1912. 
88. Smith B, Windebank A, Dyck P. Nonmalignant inflammatory sensory polyganglionopathy. Peripheral neuropathy. Philadelphia: WB Saunders 1993:1525ñ31.

89. Smith A, Bromberg M. A rational diagnostic approach to peripheral neuropathy. Journal of Clinical Neuromuscular Disease 2003;4(4):190.

90. Collins M. Localized vasculitis and the peripheral nervous system. J Rheumatol 2005;32:769-71.

91. Ramos-Casals M, Anaya J, Garcla-Carrasco M, Rosas J, BovÈ A, Claver $G$, et al. Cutaneous vasculitis in primary Sjogren syndrome: classification and clinical significance of 52 patients. Medicine 2004;83(2):96.

92. Ramos-Casals M, Nardi N, Brito-Zeron P, Aguilo S, Gil V, Delgado G, et al. Atypical autoantibodies in patients with primary Sjogren syndrome: clinical characteristics and follow-up of 82 cases. Semin Arthritis Rheum 2006;35(5):31221.

93. Vitali C, Tavoni A, Neri R, Castrogiovanni P, Pasero G, Bombardieri S. Fibromyalgia Features in Patients with Primary Sj"gren's Syndrome: Evidence of a Relationship with Psychological Depression. Scandinavian journal of rheumatology 1989;18(1):21-27.

94. Tishler M, Barak Y, Paran D, Yaron M. Sleep disturbances, fibromyalgia and primary Sj ${ }^{2}$ gren's syndrome. Clinical and experimental rheumatology; 15(1):71.

95. Ringel S, Forstot J, Tan E, Wehling C, Griggs R, Butcher D. Sjogren's syndrome and polymyositis or dermatomyositis. Archives of Neurology 1982;39(3):157.

96. Cody D, Davidson J. Juvenile dermatomyositis and Sjogren's syndrome occurring concurrently in an adolescent male. Rheumatology 2002;41(6):698.

97. Kanellopoulos P, Baltoyiannis C, Tzioufas A. Primary Sjogren's syndrome associated with inclusion body myositis. Rheumatology 2002;41(4):440.

98. $\quad$ AAkpek E-B, 1979 \#9; French, 2003 \#8; Graves, 2003 \#10; Jacobs, 1988 \#11; Khurrum Baig, 2004 \#2; Kiang, 1998 \#5; Perry, 1997 \#6; Pucci, 2002 \#4; Smith, 1981 \#12; Tang-Liu, 2005 \#1; Temprano, 2005 \#7\}. The American College of Rheumatology response criteria for proliferative and membranous renal disease in systemic lupus erythematosus clinical trials. Arthritis Rheum 2006;54(2):421-32.

99. Hocevar A, Tomsic M, Praprotnik S, Hojnik M, Kveder T, Rozman B. Parasympathetic nervous system dysfunction in primary Sjogren's syndrome. British Medical Journal 2003;62(8):702.

100. Bacman S, Perez Leiros C, Sterin-Borda L, Hubscher O, Arana R, Borda E. Autoantibodies against lacrimal gland M3 muscarinic acetylcholine receptors in patients with primary Sjogren's syndrome. Invest Ophthalmol Vis Sci 1998;39(1):151-6.

101. Bacman S, Sterin-Borda L, Camusso JJ, Arana R, Hubscher O, Borda E. Circulating antibodies against rat parotid gland $\mathrm{M} 3$ muscarinic receptors in primary Sjogren's syndrome. Clin Exp Immunol 1996;104(3):454-9. 
102. Wang F, Jackson M, Maughan V, Cavill D, Smith A, Waterman S, et al. Passive transfer of Sjgren's syndrome IgG produces the pathophysiology of overactive bladder. Arthritis \& Rheumatism 2004;50(11):3637-3645.

103. Mandl T, Granberg V, Apelqvist J, Wollmer P, Manthorpe R, Jacobsson LTH. Autonomic nervous symptoms in primary Sjogren's; syndrome.

Rheumatology 2008;47(6):914.

104. Low P, Vernino S, Suarez G. Autonomic dysfunction in peripheral nerve disease. Muscle \& Nerve 2003;27(6):646-661.

105. Alexander E. Neurologic disease in Sj'gren's syndrome: mononuclear inflammatory vasculopathy affecting central/peripheral nervous syustem and muscle. A clinical review and update of immunopathogenesis. Rheumatic diseases clinics of North America 1993;19(4):869-908.

106. Urban P, Keilmann A, Teichmann E, Hopf H. Sensory neuropathy of the trigeminal, glossopharyngeal, and vagal nerves in Sj'gren's syndrome. Journal of the neurological sciences 2001;186(1-2):59-63.

107. Alexander E. Central nervous system (CNS) manifestations of primary Sj'gren's syndrome: an overview. Scandinavian journal of rheumatology. Supplement 1986;61:161.

108. Garcia-Carrasco M, Ramos-Casals M, Rosas J, Pallares L, Calvo-Alen J, Cervera R, et al. Primary Sjogren syndrome: clinical and immunologic disease patterns in a cohort of 400 patients. Medicine 2002;81(4):270.

109. Anaya J, Villa L, Restrepo L, Molina J, Mantilla R, Vargas S. Central nervous system compromise in primary Sjogren's syndrome. JCR: Journal of Clinical Rheumatology 2002;8(4):189.

110. Mauch E, Volk C, Kratzsch G, Krapf H, Kornhuber H, Laufen H, et al. Neurological and neuropsychiatric dysfunction in primary Sjogren's syndrome. Acta Neurologica Scandinavica 1994;89(1):31-35.

111. Birnbaum J, Petri M, Thompson R, Izbudak I, Kerr D. Distinct subtypes of myelitis in systemic lupus erythematosus. Arthritis \& Rheumatism 2009;60(11):3378-3387.

112. Zeis T, Graumann U, Reynolds R, Schaeren-Wiemers N. Normalappearing white matter in multiple sclerosis is in a subtle balance between inflammation and neuroprotection. Brain 2007.

113. Noseworthy J, Bass B, Vandervoort M, Ebers G, Rice G, Weinshenker B, et al. The prevalence of primary Sj'gren's syndrome in a multiple sclerosis population. Annals of neurology 1989;25(1):95-98.

114. Sandberg-Wollheim M, Axellm T, Hansen B, Henricsson V, Ingesson E, Jacobsson L, et al. Primary Sjogren's syndrome in patients with multiple sclerosis. Neurology 1992;42(4):845.

115. MIRO J, PEN...A-SAGREDO J, Berciano J, INSU A S, Leno C, Velarde $\mathrm{R}$. Prevalence of primary Sj ${ }^{\prime}$ gren's syndrome in patients with multiple sclerosis. Annals of neurology 1990;27(5):582-584.

116. Wang Y, Tsai K, Fuh J, Tsai C, Wang S. High Frequency of Primary Sj`gren's Syndrome in Taiwanese Patients Presenting as Relapsing-Remitting Multiple Sclerosis. Eur Neurol 2004;51(1):21-25. 
117. de Seze J, Delalande S, Fauchais A, Hachulla E, Stojkovic T, Ferriby D, et al. Myelopathies secondary to Sj'gren's syndrome: treatment with monthly intravenous cyclophosphamide associated with corticosteroids. J Rheumatol 2006;33(4):709-11.

118. Pericot I, Brieva L, Tintore M, Rio J, Sastre-Garriga J, Nos C, et al. Myelopathy in seronegative Sjogren syndrome and/or primary progressive multiple sclerosis. Multiple Sclerosis 2003;9(3):256-259.

119. Tsai K, Tsai C, Liao N. Sj gren's syndrome with central nervous system involvement presenting as multiple sclerosis with failure response to betainterferon. European neurology 2001;45(1):59-60.

120. Chang C, Shiau Y, Wang J, Ho S, Kao A. Abnormal regional cerebral blood flow on 99mTc ECD brain SPECT in patients with primary Sjogren's syndrome and normal findings on brain magnetic resonance imaging. British Medical Journal 2002;61(9):774.

121. Belin C, Moroni C, Caillat-Vigneron N, Debray M, Baudin M, DUMAS J, et al. Central nervous system involvement in Sj'gren's syndrome: evidence from neuropsychological testing and HMPAO-SPECT. In; 1999: Masson; 1999. p. 598-604.

122. KAWASHIMA N, SHINDO R, KOHNO M. Primary Sj^gren"s Syndrome with Subcortical Dementia. Internal Medicine 1993;32(7):561-564.

123. Caselli R, Scheithauer B, Bowles C, Trenerry M, Meyer F, Smigielski J, et al. The treatable dementia of Sjingren's syndrome. Annals of neurology 1991;30(1):98-101.

124. Orman B, Sterin-Borda L, De Couto Pita A, Reina S, Borda E. Anti-brain cholinergic auto antibodies from primary Sj ${ }^{2}$ gren syndrome sera modify simultaneously cerebral nitric oxide and prostaglandin biosynthesis. International Immunopharmacology 2007;7(12):1535-1543.

125. Liberatore G, Jackson-Lewis V, Vukosavic S, Mandir A, Vila M, McAuliffe $W$, et al. Inducible nitric oxide synthase stimulates dopaminergic neurodegeneration in the MPTP model of Parkinson disease. Nature medicine 1999;5(12):1403-1409.

126. Kim E, Lee J, Kwon K, Lee S, Moon C, Baik E. Differential roles of cyclooxygenase isoforms after kainic acid-induced prostaglandin E2 production and neurodegeneration in cortical and hippocampal cell cultures. Brain research 2001;908(1):1-9.

127. Hassin-Baer S, Levy Y, Langevitz P, Nakar S, Ehrenfeld M. Anti- 2glycoprotein I in Sjogrenís syndrome is associated with parkinsonism. Clinical rheumatology 2007;26(5):743-747.

128. Visser L, Koudstaal P, Van de Merwe J. Hemiparkinsonism in a patient with primary $\mathrm{Sj}$ 'gren's syndrome. A case report and a review of the literature. Clinical neurology and neurosurgery 1993;95(2):141-145.

129. Hashimoto S, Sawada T, Inoue T, Yamamoto K, Iwata M. Cholinergicdrug induced sicca syndrome in Parkinson's disease::: a case report and a review of the literature. Clinical neurology and neurosurgery 1999;101(4):268270. 
130. Nishimura H, Tachibana H, Makiura N, Okuda B, Sugita M. Corticosteroidresponsive parkinsonism associated with primary Sj^gren's syndrome. Clinical neurology and neurosurgery 1994;96(4):327-331.

131. Creange A, Sedel F, Brugieres P, Voisin M, Degos J. Primary Sj gren's syndrome presenting as progressive parkinsonian syndrome. Movement disorders 1997;12(1):121-123.

132. Walker R, Spiera H, Brin M, Olanow C. Parkinsonism associated with $S j$ 'gren's syndrome: three cases and a review of the literature. Movement disorders 1999;14(2):262-268.

133. Venegas Fanchke $P$, Sinning M, Miranda M. Primary Sj^gren's syndrome presenting as a generalized Chorea. Parkinsonism and Related Disorders 2005;11(3):193-194.

134. Papageorgiou S, Kontaxis T, Bonakis A, Kalfakis N. Orofacial dystonia related to Sjogrenís syndrome. Clinical rheumatology 2007;26(10):1779-1781. 135. Alexander E, Alexander G. Aseptic meningoencephalitis in primary Sjogren's syndrome. Neurology 1983;33(5):593.

136. Hirohata M, Yasukawa Y, Ishida C, Komai K, Yamada M. Reversible cortical lesions in primary Sj'gren's syndrome presenting with meningoencephalitis as an initial manifestation. Journal of the neurological sciences 2005;232(1-2):111-113.

137. Rossi R, Valeria Saddi M. Subacute aseptic meningitis as neurological manifestation of primary Sj'gren's syndrome. Clinical neurology and neurosurgery 2006;108(7):688-691.

138. Ishida $\mathrm{K}$, Uchihara $\mathrm{T}$, Mizusawa $\mathrm{H}$. Recurrent aseptic meningitis: a new CSF complication of Sjogren's syndrome. Journal of neurology 2007;254(6):806807.

139. Hoshina T, Yamaguchi Y, Ohga S, Kira R, Ishimura M, Takada H, et al. Sjogren's syndrome-associated meningoencephalomyelitis: Cerebrospinal fluid cytokine levels and therapeutic utility of tacrolimus. Journal of the neurological sciences 2007.

140. Caselli R, Scheithauer B, O'Duffy J, Peterson G, Westmoreland B, Davenport $P$. Chronic inflammatory meningoencephalitis should not be mistaken for Alzheimer's disease. In; 1993; 1993. p. 846.

141. Gerraty R, McKelvie P, Byrne E. Aseptic meningoencephalitis in primary Sj'gren's syndrome. Acta Neurol Scand 1993;88:309-311.

142. Niemel\%o R, Hakala M. Primary Sj'gren's syndrome with severe central nervous system disease. In; 1999: Elsevier; 1999. p. 4-13.

143. Wong S, Pollock A, Burnham J, Sherry D, Dlugos D. Acute cerebellar ataxia due to Sjogren syndrome. Neurology 2004;62(12):2332.

144. Hayashi Y, Kimura A, Kato S, Koumura A, Sakurai T, Tanaka Y, et al. Progressive multifocal leukoencephalopathy and CD4+ T-lymphocytopenia in a patient with Sj"gren syndrome. Journal of the neurological sciences 2008;268(12):195-198.

145. Li J, Lai P, Lam H, Lu L, Cheng H, Lee J, et al. Hypertrophic cranial pachymeningitis and lymphocytic hypophysitis in Sjogrenís syndrome. Neurology 1999;52(2):420. 
146. Alexander E, Ranzenbach M, Kumar A, Kozachuk W, Rosenbaum A, Patronas N, et al. Anti-Ro (SS-A) autoantibodies in central nervous system disease associated with Sjogren's syndrome (CNS-SS): Clinical, neuroimaging, and angiographic correlates. Neurology 1994;44(5):899.

147. Spezialetti R, Bluestein H, Peter J, Alexander E. Neuropsychiatric disease in Sj'gren's syndrome: Anti-ribosomal $P$ and anti-neuronal antibodies ${ }^{*} 1$. The American journal of medicine 1993;95(2):153-160.

148. Arnett F, Reichlin M. Lupus hepatitis: an under-recognized disease feature associated with autoantibodies to ribosomal $P$. The American journal of medicine 1995;99(5):465-472.

149. Moll J, Markusse H, Pijnenburg J, Vecht C, Henzen-Logmans S. Antineuronal antibodies in patients with neurologic complicat'lons of primary Sjogren's syndrome. Neurology 1993;43(12):2574.

150. Owada K, Uchihara T, Ishida K, Mizusawa H, Watabiki S, Tsuchiya K. Motor weakness and cerebellar ataxia in Sj'gren syndrome--identification of antineuronal antibody: a case report. Journal of the neurological sciences 2002;197(1-2):79-84.

151. Shams' ili S, Grefkens J, de Leeuw B, van den Bent M, Hooijkaas H, van der Holt B, et al. Paraneoplastic cerebellar degeneration associated with antineuronal antibodies: analysis of 50 patients. Brain 2003;126(6):1409.

152. Bourahoui A, De Seze J, Guttierez R, Onraed B, Hennache B, Ferriby D, et al. CSF isoelectrofocusing in a large cohort of MS and other neurological diseases. European Journal of Neurology 2004;11(8):525-529.

153. Vrethem M, Ernerudh J, Lindstr'm F, Skogh T. Immunoglobulins within the central nervous system in primary Sj'gren's syndrome. Journal of the neurological sciences 1990;100(1-2):186.

154. Cauli A, Yanni G, Pitzalis C, Challacombe S, Panayi G. Cytokine and adhesion molecule expression in the minor salivary glands of patients with Sjogren's syndrome and chronic sialoadenitis. British Medical Journal 1995;54(3):209.

155. ALEXANDER E, BEALL S, GORDON B, SELNES O, YANNAKAKIS G, PATRONAS N, et al. Magnetic resonance imaging of cerebral lesions in patients with the Sjogren syndrome. Annals of internal medicine 1988;108(6):815.

156. Morgen K, McFarland H, Pillemer S. Central nervous system disease in primary Sj'grenís syndrome: The role of magnetic resonance imaging. In; 2004: Elsevier; 2004. p. 623-630.

157. Kao C, Ho Y, Lan J, ChangLai S, Chieng P. Regional cerebral blood flow and glucose metabolism in Sjogren's syndrome. Journal of Nuclear Medicine 1998;39(8):1354.

158. Kao C, Lan J, ChangLai S, Chieng P. Technetium-99m-HMPAO SPECT and MRI of brain in patients with neuro-Behcet's syndrome. Journal of Nuclear Medicine 1998;39(10):1707.

159. Lass P, Krajka-Lauer J, Homziuk M, Iwaszkiewicz-Bilikiewicz B, Koseda $M$, Hebanowski M, et al. Cerebral blood flow in Sjogren's syndrome using 99Tcm-HMPAO brain SPET. Nuclear medicine communications 2000;21(1):31. 
160. Tan EM. Antinuclear antibodies. Diagnostic markers for autoimmune diseases and probes for cell biology. Adv. Immunol. 1989;44:93-151.

161. Tan EM, Feltkamp TE, Smolen JS, Butcher B, Dawkins R, Fritzler MJ, et al. Range of antinuclear antibodies in "healthy" individuals. Arthritis Rheum 1997;40(9):1601-11.

162. Tan EM, Smolen JS, McDougal JS, Butcher BT, Conn D, Dawkins R, et al. A critical evaluation of enzyme immunoassays for detection of antinuclear autoantibodies of defined specificities. I. Precision, sensitivity, and specificity. Arthritis Rheum 1999;42(3):455-64.

163. Infirmary E, Stone J, Caruso P, Deshpande V. Case 24-2009: A 26-YearOld Woman with Painful Swelling of the Neck. N Engl J Med 2009;361:511-8.

164. Craig W, Ledue T, Johnson A, Ritchie R. The distribution of antinuclear antibody titers in normal children and adults. Journal of rheumatology 1999;26(4):914-919.

165. Rosler M, Anand R, Cicin-Sain A, Gauthier S, Agid Y, Dal-Bianco P, et al. Efficacy and safety of rivastigmine in patients with Alzheimer's disease: international randomised controlled trialï Commentary: Another piece of the Alzheimer's jigsaw. British Medical Journal 1999;318(7184):633.

166. Caroyer J, Manto M, Steinfeld S. Severe sensory neuronopathy responsive to infliximab in primary Sjogren's syndrome. Neurology 2002;59(7):1113.

167. Kizawa M, Mori K, lijima M, Koike H, Hattori N, Sobue G. Intravenous immunoglobulin treatment in painful sensory neuropathy without sensory ataxia associated with Sjogren's syndrome. British Medical Journal 2006;77(8):967. 168. Takahashi Y, Takata T, Hoshino M, Sakurai M, Kanazawa I. Benefit of IVIG for long-standing ataxic sensory neuronopathy with Sjogren's syndrome. Neurology 2003;60(3):503.

169. Rajabally $Y$, Seow H, Abbott R. Immunoglobulin-responsive dysautonomia in Sj'gren's syndrome. Journal of neurology 2007;254(5):674-675.

170. Chen W, Yeh J, Chiu H. Plasmapheresis in the treatment of ataxic sensory neuropathy associated with $\mathrm{Sj}$ 'grenís syndrome. European neurology 2000;45(4):270-274.

171. Gorson K, Natarajan N, Ropper A, Weinstein R. Rituximab treatment in patients with IVIg-dependent immune polyneuropathy: a prospective pilot trial. Muscle and Nerve 2007;35(1):66-69.

172. Asahina M, Kuwabara S, Nakajima M, Hattori T. D-penicillamine treatment for chronic sensory ataxic neuropathy associated with Sjingren's syndrome. Neurology 1998;51(5):1451-1453.

173. Wyszynski A, Wyszynski B. Treatment of depression with fluoxetine in corticosteroid-dependent central nervous system Sjogren's syndrome.

Psychosomatics 1993;34(2):173.

174. Pascual J, Cid C, Berciano J, GRANT I, DYCK P. HIGH-DOSE IV IMMUNOGLOBULIN FOR PERIPHERAL NEUROPATHY ASSOCIATED WITH SJOGREN'S SYNDROME. AUTHORS' REPLY. Neurology 1998;51(2):650-651. 175. ALEXANDER E, MALINOW K, LEJEWSKI J, JERDAN M, PROVOST T, ALEXANDER G. Primary Sjogren's syndrome with central nervous system 
disease mimicking multiple sclerosis. Annals of internal medicine 1986;104(3):323.

176. Ozgocmen S, Gur A. Treatment of Central Nervous System Involvement Associated with Primary Sjogrens Syndrome. Current pharmaceutical design 2008;14(13):1270-1273.

177. Williams C, Butler E, Roman G. Treatment of myelopathy in Sjogren syndrome with a combination of prednisone and cyclophosphamide. Archives of Neurology 2001;58(5):815.

178. Rogers S, Williams C, Roman G. Myelopathy in Sjogrens Syndrome: Role of Nonsteroidal Immunosuppressants. Drugs 2004;64(2):123-132.

179. Wright R, O'Duffy J, Rodriguez M. Improvement of myelopathy in Sjigren's syndrome with chlorambucil and prednisone therapy. Neurology 1999;52(2):386. 180. Yamout B, El-Hajj T, Barada W, Uthman I. Successful treatment of refractory neuroSjogren with Rituximab. Lupus 2007;16(7):521.

181. Canhao H, Fonseca J, Rosa A. Intravenous gammaglobulin in the treatment of central nervous system vasculitis associated with Sj ${ }^{\wedge}$ gren's syndrome. The Journal of rheumatology 2000;27(4):1102.

182. Konttinen $\mathrm{Y}$, Kinnunen $\mathrm{E}$, Martin Von Bonsdorff M, Lillqvist $\mathrm{P}$, Immonen I, Bergroth $\mathrm{V}$, et al. Acute transverse myelopathy successfully treated with plasmapheresis and prednisone in a patient with primary sj'ugren's syndrome. Arthritis Care \& Research;30(3):339-344.

183. Mavragani C, Moutsopoulos $\mathrm{H}$. Conventional therapy of Sjogrenís Syndrome. Clinical Reviews in Allergy and Immunology 2007;32(3):284-291. 184. Szechtman H, Sakic B, Denburg J. Review: Behaviour of MRL Mice: An Animal Model of Disturbed Behaviour in Systemic Autoimmune Disease. Lupus 1997;6(3):223.

185. Tomita M, Holman B, Williams L, Pang K, Santoro T. Cerebellar dysfunction is associated with overexpression of proinflammatory cytokine genes in lupus. Journal of Neuroscience Research 2001;64(1):26-33.

186. Arnsten A. Stress signalling pathways that impair prefrontal cortex structure and function. Nature Reviews Neuroscience 2009;10(6):410-422. 187. Luethi M, Meier B, Sandi C. Stress effects on working memory, explicit memory, and implicit memory for neutral and emotional stimuli in healthy men. Frontiers in Behavioral Neuroscience 2008;2.

188. Waterman SA, Gordon TP, Rischmueller M. Inhibitory effects of muscarinic receptor autoantibodies on parasympathetic neurotransmission in Sjogren's syndrome. Arthritis Rheum 2000;43(7):1647-54. 